CRPL-D30

Nationa! Bureau of Standards

AUG 211947
UNITED STATES DEPARTMENT OF COMMERCE

W. AVERELL HARRIMAN, Secretary

NATIONAL BUREAU OF STANDARDS

E. U. Condon, Director

\title{
BASIC RADIO PROPAGATION PREDICTIONS FOR MAY 1947
}

\section{THREE MONTHS IN ADVANCE}

\section{ISSUED FEBRUARY 1947}

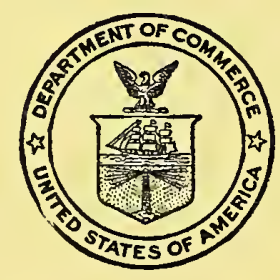

[Published with approval of the Director of the Budget]

PREPARED BY CENTRAL RADIO PROPAGATION LABORATORY

National Bureau of Standards

Washington 25, D. C. 


\section{NATIONAL BUREAU OF STANDARDS \\ CENTRAL RADIO PROPAGATION LABORATORY}

Basic Radio Propagation Predictions are prepared by the staff of the Central Radio Propagation Laboratory of the National Bureau of Standards under the direction of J. Howard Dellinger, Chief, and Newbern Smith, Assistant Chief.

The monthly reports of this CRPL-D series are distributed to the Army as the TB 11-499 series, by The Adjutant General; to the Navy as the DNC-13-1 series, by the Registered Publications Section, Division of Naval Communications; and to others by the CRPL.

The CRPL-D series is a monthly supplement to the IRPL Radio Propagation Handbook, Part 1, issued by the Army as TM 11-499 and by the Navy as DNC-13-1, and is required in order to make practical application of the basic Handbook.

Beginning with the July 1946 issue the CRPL-D series, "Basic Radio Propagation Predictions," is available on a purchase basis from the Superintendent of Documents, U. S. Government Printing Office, Washington 25, D. C., on the following terms:

Single copy
Annual subscription (12 issues)

New subscribers and those desiring to continue to receive this publication should place their orders with the Superintendent of Documents.

The rules of the Superintendent of Documents require that remittances be made in advance, either by coupons sold in sets of 20 for $\$ 1$ and good until used, or by check or money order payable to the Superintendent of Documents. Currency, if used, is at sender's risk. Postage stamps, foreign money, and defaced or smooth coins are not acceptable. Postage is not required in the United States, to United States possessions, and to countries extending franking privileges. For mailing to other countries, an additional amount of about one-third of the purchase price is required. Remittances from foreign countries should be by international money order payable to the Superintendent of Documents or by draft on an American bank. 


\section{BASIC RADIO PROPAGATION PREDICTIONS FOR MAY 1947 THREE MONTHS IN ADVANCE}

Comments are invited from users of this report as to the accuracy of predictions when applied to the solution of specific radio propagation problems. Such comments or queries concerning radio propagation should be addressed as follows:

For the Army:

Office of the Chief Signal Officer, War Dept.

Washington 25, D. C.

Attention: SIGOL-2.
For the Navy:

Chief of Naval Operations,

Navy Department,

Washington 25, D. C.

(CNC-20-F).

For Others:

Central Radio Propagation Laboratory,

National Bureau of Standards,

Washington 25, D. C.

\section{CONTENTS}

I. Terminology

World map showing zones covered by prediction charts, and auroral zones_- Fig. 1

F2-zero-muf, in Mc, $W$ zone, predicted for May 1947

F2-4000-muf, in Mc, $W$ zone, predicted for May 1947 ........ Fig. 6

F2-zero-muf, in Mc, $I$ zone, predicted for May 1947_... Fig. 7 F2-4000-muf, in Mc, I zone, predicted

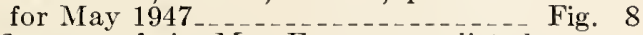
$F 2$-zero-muf, in Mc, $E$ zone, predicted for May 1947 ................... 9

$F 2-4000-$ muf, in $M c, E$ zone, predicted for May 1947 -layer $2000-$ muf, in Mc, predicted for May 1947

Median $f E s$, in Mc, predicted for May 1947

Percentage of time occurrence for Es2000-muf in excess of $15 \mathrm{Mc}$, predicted for May 1947

Fig. 15

III. Determination of great-circle distances, bearings, location of transmission control points _ Page 2 Great-circle chart, centered on equator_- Fig. 2 Diagram of transmission path auxiliary to explanation of use of distancebearing nomogram, figure 4
III. Determination, etc--Continued.

Nomogram for obtaining great-circle distances, bearings, latitude and longitude of transmission control points. Conversion scale for various distance units _. . . . . Fig. 4

IV. Calculation of maximum usable frequencies, optimum working frequencies
Nomograms for transforming $F 2$-zeromuf and $F 2-4000$-muf to equivalent maximum usable frequencies at intermediate transmission distances; conversion scale for obtaining optimum working frequencies

Nomogram for transforming $E$-layer 2000-muf to equivalent maximum usable frequencies and optimum working frequencies due to combined effect of $E$ layer and $F 1$ layer at other transmission distances................ Fig. 14

V. Absorption, distance range, and lowest useful

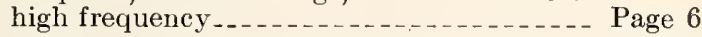

VI. Sample muf and owf calculations___._._._. Page 6

For short paths (under $4000 \mathrm{~km}$ ), page 6 , table 1 , and figure 16 .

For long paths (over $4000 \mathrm{~km}$ ), page 7; table 2, and figure 17 . 


\section{TERMINOLOGY}

The following symbols are used, as recommended by the International Radio Propagation Conference held in Washington, D. C., 17 April to 5 May 1944.

$$
\begin{aligned}
& f^{\circ} F 2= \text { ordinary-wave critical frequency } \\
& \text { for the } F 2 \text { layer. } \\
& F^{x} F 2=\text { extraordinary-wave critical fre- } \\
& \text { quency for the } F 2 \text { layer. } \\
& E s=\text { sporadic, or abnormal, } E \text {. } \\
& f E s= \text { highest frequency of } E s \text { reflec- } \\
& \text { tions. }
\end{aligned}
$$

muf or $\mathrm{MUF}=$ maximum usable frequency.

owf or $\mathrm{OWF}=$ optimum working frequency.

4000 -muf chart $=$ contour chart of muf for 4000 kilometer paths.

2000-muf chart $=$ contour chart of muf for 2000kilometer paths.

Zero-muf chart=contour chart of vertical-incidence critical frequency, extraordinary wave $\left(f^{x} F 2\right)$.

\section{WORLD-WIDE PREDICTION CHARTS AND THEIR USES}

The charts, figures 5 to 11 , present world-wide predictions of monthly average maximum usable frequencies for May 1947. Conditions may be markedly different on disturbed days, especially in or near the auroral zones, shown on the map of figure 1. The method of prediction as discussed in the IRPL Rodio Propagation Handbook, Part 1, War Dept. TM 11-499, Navy Dept. DNC-13-1, p. 52,53 , has been modified, substantially as indicated in reports IRPL-R11, 15, 16, and 19 .

Although ionosphere characteristics are roughly similar for locations of equal latitude, there is also considerable variation with longitude, especially in the case of the $F 2$ layer. This "longitude effect" seems to be related to geomagnetic latitude. Attention was first called to this effect in the report "Radio Propagation Conditions" issued 10 Sept. 1943; it was brought into general operational use in the next issuc (14 Oct. 1943).

The longitude effect in the $F_{2}$ layer is taken care of by providing world charts for three zones, in each of which the ionosphere characteristics are considered independent of longitude for practical purposes. These zones are indicated on the world map, figure 1 .

Two $F 2$ charts are provided for each zone, one of which, the "zero-muf chart," shows the verticalincidence muf, or the critical frequency for the extraordinary wave, and the other, the "4000- muf chart," shows the muf for a transmission distance of $4000 \mathrm{~km}$. Do not confuse the zero-muf charts with the $f^{\circ} \mathrm{F} 2$ charts appearing in the previous IRPL reports "Radio Propagation Conditions." (Values of F2-zero-muf exceed those of $f^{\circ} \mathrm{F} 2$ for the same location and local time by an amount approximately equal to half the gyrofrequency for the location. See IRPL Radio Propagation Handbook, Part 1 (War Dept. TM 11-499 and Navy Dept. DNC-13-1), p. 18, 19, 28, and fig. 9.)

The longitude variation is operationally negligible in the case of the normal $E$ layer and therefore only one $E$-layer chart is provided.

The variation of $f E s$ with geomagnetic latitude seems to be well marked and important. Consequently, the $f E s$ charts are constructed on the basis of geomagnetic latitude.

Since there are as yet insufficient correlated data, the $f E s$ charts are much less precise than the other charts. Instructions for use of these charts appear in section IV, 3 .

Attention is called to the fact that the 50-percent contour in figure 15, "Percentage of Time Occurrence for Es-2000-muf in Excess of $15 \mathrm{Mc}$," does not necessarily coincide with the $3-\mathrm{Mc}$ contour in figure 12, "Median $\mathrm{fEs}$, in Mc," because the two charts are prepared independently.

\section{DETERMINATION OF GREAT-CIRCLE DISTANCES, BEARINGS, AND LOCATION OF TRANSMISSION CONTROL POINTS \\ 1. BY USE OF THE WORLD MAP AND GREAT-CIRCLE CHART}

Figure 1 is a map of the world. Figure 2 is a chart to the same scale as figure 1 , on which the solid-line curves crossing the equator at a single point represent great circles. The numbered dotdash lines crossing the great circles indicate distances along them in thousands of kilometers. In using figures 1 and 2 , procecd as follows:

a. Place a piece of transparent paper over the map, figure 1, and draw the equatorial line (zero degrees). Place dots over the locations of the transmitting and receiving stations. Also mark the meridian whose local times are to be used as the times for calculation. Usually the Greenwich meridian is used.

$b$. Place this transparency over the chart, figure 2 , and, keeping the equatorial line of the transparency always on the equatorial line of figure 2, slide the transparency horizontally until the terminal points marked on it fall either on the same great circle or the same proportional distance between adjacent great-circle curves. Draw in the path.

c. For paths shorter than $4000 \mathrm{~km}$, locate the 
midpoint of the path, keeping the transparency in positiou on figure 2 and using as a distance scale the points at which the numbered lines in figure 2 cross the path as drawn on the transparency.

d. For paths longer than $4000 \mathrm{~km}$, designating the ends as the $A$-end and $B$-end, respectively, lo- cate on the path and mark with a dot the following "control points," scaling the distances as in $c$ above:

For $F 2$ layer, points $A$ and $B, 2000$ kin from each end.

For $E$ layer, points $A^{\prime}$ and $B^{\prime}, 1000 \mathrm{~km}$ from each end.

\section{BY USE OF THE NOMOGRAM OF FIGURE 4}

Note.-Values near the ends of the nomogram scales of figure 4 are subject to error because the scales are compressed. If exact values are required in those regions, they should be calculated by means of the usual trigonometric formulas.

In figure $3, Z$ and $S$ are the locations of the transmitting and receiving stations, where $Z$ is the west and $S$ the east end of the path. If $a$ point lies in the Southern Hemisphere, its angle of latitude is always taken as negative. NorthernHemisphere latitudes are taken as positive.

\section{a. To obtain the great-circle distances ZS (short route):}

(1) Draw a slant line from (lat. Z-lat. $S$ ) measured up from the bottom on the left-hand scale to (lat. $Z$ +lat. $S$ ) measured down from the top of the right-hand scale. If (lat. $Z$-lat. $S$ ) or (lat. $Z$ +lat. $S$ ) is negative, regard it as positive.

(2) Determine the separation in longitude of the stations. Regard as positive. If the angle so obtained is greater than $180^{\circ}$, then subtract from $360^{\circ}$. Measure this angle along the bottom scale, and erect a vertical line to the slant line obtained in (1).

(3) From the intersection of the lines draw a horizontal line to the left-hand scale. This gives $Z S$ in degrees.

(4) Convert the distance $Z S$ to kilometers, miles, or nautical miles, by using the scale at the bottom of figure 4.

Note.-The long great-circle route in degrees is simply $360^{\circ}-Z S$. The value will always be greater than $180^{\circ}$. Therefore, in order to obtain the distance in miles from the conversion scale, the value for the degrees in excess of $180^{\circ}$ is added to the value for $180^{\circ}$.

b. To obtain the bearing angle PZS (short route):

(1) Subtract the slort-route distance $Z S$ in degrees obtained in a from $90^{\circ}$ to get $h$. The value of $h$ may be negative, and should be substituted in (2) below without change of sign.

(2) Draw a slant line from (lat. Z $-h$ ) measured up from the bottom on the left-hand scale to (lat. $Z+h$ ) measured down from the top on the right-hand scale. If (lat. $Z-h$ ) or (lat. $Z+h)$ is negative, regard it as positive.

(3) From $\left(90^{\circ}\right.$ - lat. $\left.S\right)$ mcasured up from the bottom on the left-hand scale, draw a horizontal line until it intersects the previous slant line.

(4) From the point of intersection draw a vertical line to the bottom scale. This gives the bearing angle $P Z S$. The angle may be either east or west of north, and must be determined by inspection of a map.

\section{c. To obtain the bearing angle PSZ:}

(1) Repeat steps (1), (2), (3), and (4) in $b$, interchanging $Z$ and $S$ in all computations. The result obtained is the intcrior angle $P S Z$ in degrees.

(2) The bearing angle $P S Z$ is $360^{\circ}$ minus the result obtained in (1) (as bearings are customarily given clockwise from due north).

Note.-The long-route bearing angle is simply obtained by adding $180^{\circ}$ to the short-route value as determined in $b$ or $c$ above.

d. To obtain the latitude of $Q$ (mid-or other point of path):

(This calculation is in principle the converse of $b$.)

(1) Obtain $Z Q$ in degrees. If $Q$ is the midpoint of the path, $Z Q$ will be equal to one-half, $Z S$. If $Q$ is one of the $2000-\mathrm{km}$ "control points," $Z Q$ will be approximately $18^{\circ}$, or $Z S-18^{\circ}$.

(2) Subtract $Z Q$ from $90^{\circ}$ to get $h^{\prime}$. The value of $h^{\prime}$ may be negative, and should be substituted in (3) below without change of sign.

(3) Draw a slant line from (lat. $Z-h^{\prime}$ ) measured up from the bottom on the left-hand scale, to (lat. $Z+h^{\prime}$ ) measured down from the top on the right-hand scale. If (lat. $Z-h^{\prime}$ ) or (lat. $\left.Z+h^{\prime}\right)$ is negative, regard it as positive.

(4) From the bearing angle $P Z S$ (taken always as less than $180^{\circ}$ ) measured to the right on the bottom scale, draw a vertical line to meet the above slant linc.

(5) From this intersection draw a horizontal linc to the left-hand scale.

(6) Subtract the reading given from $90^{\circ}$ to give the latitude of $Q$. (If the answer is negative, then $Q$ is in the Southern Hemisphere.)

\section{e. To obtain the longitude difference $t^{\prime}$ between $Z$ and $Q$ :}

(This calculation is in principle the converse of $a$.)

(1) Draw a straight line from (lat. $Z$-lat. Q) measured up from the bottom on the left-hand scale to (lat. $Z$ +lat. $Q$ ) measured down from the top on the right-hand scale. If (lat. $Z$-lat. Q) or (lat. $Z$ +lat. $Q$ ) is negative, regard it as positive.

(2) From the left-hand side, at $Z Q$, in degrees, draw a horizontal line to the above slant line.

(3) At the intersection drop a vertical line to the bottom scale, which gives $t^{\prime}$ in degrees. 


\section{CALCULATION OF MAXIMUM USABLE FREQUENCIES, OPTIMUM WORKING FREQUENCIES}

\section{PROCEDURE FOR DETERMINATION OF MUF AND OWF FOR TRANSMISSION DISTANCES UNDER 4000 KM (PROPAGATION BY THE REGULAR LAYERS)}

a. Prepare or obtain work forms similar to CRPL form $A F$ (see table 1). Note that form $A F$ provides for the inclusion of sporadic $E(E s)$, which will be discussed under 3 below.

In following the instructions of this section (for propagation by the regular layers) form AF should be modifiea by onitting columus $a, b, f, i$ and $j$. The item on procedure in column $m$ should read: "Higher of $g, h$," and in column $n$ : "Higher of $k, l$. ",

$b$. Locate the midpoint of the transmission path using the methods of section III above and by laying the great-circle path transparency back on the world map of figure 1 , with the ends of the path in their proper location, determine in which geographical zone, $E, I$, or $W$, the midpoint falls.

$c$. To determine the maximum usable frequency (muf):

(1) Place the great-circle transparency over the F2-zero-muf chart for the proper zone of the midpoint of the path, and, keeping the equatorial line of the transparency over the equatorial line of the chart, slide the transparency horizontally until the Greenwich meridian coincides with either 00 or 24 (not labeled) on the time scale.

Note that all points on the great-circle path are in their proper local time relationship to Greenwich because 24 hours on the time scale of a muf chart is drawn to the same scale as $360^{\circ}$ of longitude on the world map.

(2) Read the value of F2-zero-muf for the midpoint of the path and enter in column $d$ of form $\mathrm{AF}$.

(3) Repeat for $02 ; 04$, etc., on the time scale. Frequently it will be necessary to make the Greenwich meridian of the transparency coincide with an imagined 26, 28, etc., on the time scale. A convenient aid is to place marks at two-hour intervals on the equatorial line of the transparency.

(4) Repeat steps (1), (2), and (3) for the
F2-4000-muf chart for the proper zone and again for the E-layer 2000-muf chart, figure 11, entering values in columns $e$ and $c$, respectively.

(5) For each hour place a straightedge between the values of $F^{\prime} 2$-zero-muf and $F 2-4000$ muf at the left- and right-hand sides, respectively, of the grid nomogram, figure 13 , and read the value of the muf for the actual path length at the intersection point of the straightedge with the appropriate vertical distance line. Enter in column $h$.

\section{Eæample:}

$F 2$-zero-muf $=6.8$ Mc. $\quad F 2$-4000-muf $=23.0$ Mc. For a distance of $2600-\mathrm{km}$ the $F 2$ muf is $19.1 \mathrm{Mc}$.

(6) For each hour place a straightedge between the value of the E-layer 2000-muf on the left-hand scale of the nomogram, figure 14, and the value of the path length on the right-hand scale, and read the $E-F 1$-muf for that path length, off the central scale. (Example on nomogram.) Enter in column $g$.

(7) Compare the values of muf obtained by operations (1) to (6). The higher of the two values (columns $g$ and $h$ of form $\mathrm{AF}$ ) thus determined is the muf for the path. Enter in column $m$.

$d$. To determine the optimum working frequency (owf):

(1) Calculate the $F 2$-owf from the F2-muf determined under $c$ above by multiplying each figure in column $h$ by 0.85 or by using the conversion scale in figure 13. Enter in column $l$.

(2) Use for the $E$-owf the value of E-F1-muf determined under $c(6)$ above. This represents a change from the previous practice of taking 97 percent of the E-F1-muf on the nomogram of figure 14. Enter in column $k$.

(3) Compare the F2-owf and E-owf. The higher of the two values (columns $k$ and $l$ of form $\mathrm{AF}$ ) is that of the path owf. Enter in column $n$.

\section{PROCEDURE FOR DETERMINATION OF MUF AND OWF FOR TRANSMISSION DISTANCES GREATER THAN 4000 KM (PROPAGATION BY THE REGULAR LAYERS)}

a. General considerations:

The procedure outlined below is based on the following assumptions:

(1) That there are F2-layer control points $A$ and $B$ and E-layer control points $A^{\prime}$ and $B^{\prime}$. (See section III, $1 d$ above.)

(2) That the highest frequency that will "take off" along the path at the $A$-end is the highest frequency that can be propagated at $A$ and $A^{\prime}$ considererl together.

(3) That the highest frequency that will come in along the path at the $B$-end is the highest frequency that can be propagated at $B$ and $B^{\prime}$ considered together.

(4) That the highest frequency that can be propagated from the $A$-end to the $B$-end is the lower of the two frequencies of (2) and (3) above.

(5) That the frequency obtained in (4) is the same for propagation from the $B$-end to the $A$-end. b. Prepare or obtain work forms similar to CRPL form AH (see table 2). Note that form AH provides for the inclusion of the effects of sporadic $E$ (Es), which will be discussed under 3 below. 
In following the instructions of this section (for propagation by the regular layers) form $\mathrm{AH}$ should be modified by omitting columns $a, b, e, g, h$, and $k$. The item on procedure in column $m$ should read: "Higher of $c, d ;$ " in column $n$ : "Higher of $i, j ;$ " in column 0 : "Higher of $d, f$," and in column $p$ : "Higher of $j, l$."

$c$. Locate the control points $A$ and $A$ ' at one end of the path and $B$ and $B^{\prime}$ at the other end of the path as explained under section III, $1 d$ above. For very long paths the "short route" (minor arc of the great-circle path) and the "long route" (major arc) need be considered. Placing the transparency back on the world map, determine as in section IV, $1 b$ above, in which geographical zone, $E, I$, or $W$, each of the control points $A$ and $B$ falls.

\section{d. To determine the muf:}

(1) Place the great-circle transparency over the F2-4000-muf chart for the zone of control point $A$ and, keeping the equatorial line of the transparency over the equatorial line of the chart, slide the transparency horizontally until the Greenwich meridian coincides with either 00 or 24 (not labeled) on the time scale.

(2) Read the value of $F 2-4000$-muf for control point $A$. Enter in column $c$ of form $\mathrm{AH}$.

(3) Repeat for 02, 04, etc. on the time scale. Frequently it will be necessary to make the Greenwich meridian of the transparency coincide with an imagined 26,28 , etc., on the time scale. A convenient aid is to place marks at two-hour intervals on the equatorial line of the transparency.

(4) Repeat steps (1), (2), and (3) on the $E$ layer 2000-muf chart, figure 11, using control point $A^{\prime}$. Enter values in column $d$.

(5) Determine the muf for the $A$-end as the higher of the $F 2-4000-$ muf, column $c$, and the $E$ - layer 2000-muf, column $d$. Enter in column $m$.

(6) Read the value of $F 2$-4000-muf for control point $B$, using the $F 2-4000$-muf chart for the proper zone. Enter values in column $i$.

(7) Repeat for 02, 04, etc. on the time scalc.

(8) Read the values of E-layer 2000-muf on the E-layer 2000-1nuf chart, figure 11, using control point $B^{\prime}$. Enter values in column $j$.

(9) Determine the muf for the $B$-end as the higher of the $F 2-4000$-muf, column $i$, and the $E$ layer 2000-muf, column $j$. Enter in column $n$.

(10) Compare the two muf values of columns $m$ and $n$. The lower of the two is the muf for the transmission path under consideration. Enter in column $q$.

$e$. To determine the owf:

(1) Use the scaled data of the previous procedure.

(2) Multiply the F2-4000-muf for the $A$-end, column $c$, by 0.85 , or use the conversion scale in figure 13 , to obtain the $F 2-4000$-owf for the $A$-end, column $f$.

(3) Multiply the $F 2-4000$-muf for the $B$-end, column $i$, by 0.85 or use the conversion scale in figure 13 , to obtain the $F 2-4000$-owf for the $B$-end, column $l$.

(4) Compare the F2-4000-owf for the $A$-end, column $f$, with the $E$-layer 2000 -muf for the $A$-end, column $d$. The higher of the two is the owf for the $A$-end. Enter in column 0 .

(5) Compare the $F 2-4000$-owf for the $B$-end, column $l$, with the $E$-layer 2000 -muf for the $B$-end, column $j$. The higher of the two is the owf for the $B$-end. Enter in column $p$.

(6) Compare the two owf values of columns $o$ and $p$. The lower of the two is the owf for the transmission path under consideration. Enter in column $r$.

\section{PROCEDURES FOR INCLUSION OF THE EFFECTS OF $E_{s}$}

Sporadic- $E$ (Es) propagation may often allow' regular transmission when regular $E$ - or $F 2$-layer propagation would not. $E s$ data are not yet sufficient to permit accurate calculations of such propatation, but the $f E s$ charts of figures 12 and 15 are given as a guide to Es occurrence.

As the $f E s$ charts are constructed from considerations of geomagnetic latitude, three latitude scales are provided at the right of the charts of figures 12 and 15 , one for each of the three zones of figure $1(E, I$, and $W)$.

Until further improvements are made, the following procedures should be used to include the effects of $E s$ in the calculations of muf and owf.

$a$. For paths over $4000 \mathrm{~km}$ long:

(1) Place the great-circle path transparency prepared in section. III, 1 , over the median fEs chart, figure 12 , using the latitude scale for the zone containing the control point.

(2) Scale $f E s$ at control points $A^{\prime}$ and $B^{\prime}$. Enter in columns $a$ and $g$, respectively, on form AH.
(3) Multiply $f E s$ by 5 in each case, obtaining the $E s$-2000-muf. Enter in columns $b$ and $h$, respectively.

(4) In the determination of muf modify the procedure (steps (5) and (9)) of section $I^{5}, 2 d$ above to obtain the muf for the $A$ - and $B$-ends, respectively, as the highest of the three items, the F2-4000-muf, the E-laver 2000-muf, and the Es2000-muf. No other change is necessary.

(5) In the determination of owf subtract $4 \mathrm{Mc}$ from the $E s-2000-m u f$ to obtain the $E s-2000$-owf for the $A$-end and $B$-end, respectively, entering the results in columns $e$ and $k$. Then modify the procedure (steps (4) and (5)) of section IV, $2 e$ to obtain the owf for the $A$ - and $B$-ends, respectively, as the highest of the three items, the F24000-owf, the E-layer 2000-muf, and the Es-2000owf. No other changes are necessary.

$b$. For paths under $4000 \mathrm{~km}$ long:

(1) Repeat step (1) of $a$ above. 
(2) Scale $f E s$ at the midpoint of the path. Enter in columin $a$ of form $\mathrm{AF}$.

(3) Multiply fEs by 5, obtaining the Es-2000muf. Enter in column $b$.

(4) In the determination of muf under IV, $1 c$, find the $E s$-inuf for the path by use of the same nomogram, figure 14 , as was used for the $E-F 1$ muf, applying the Es-2000-muf to the left-hand scale and reading the answer on the middle scale. Enter in colum $f$. Then modify the procedure in IV, $1 c(7)$, so that the highest of the three values, the F2-muf, the E-F1-muf, and the Es-muf, columns $h, g, f$, is the muf for the path.

(5) In the determination of owf under IV, $1 d$, subtract $4 \mathrm{Mc}$ from the Es-2000-muf found under (3) above to obtain the Es-2000-owf, entering in column $i$. Now find the $E s$-owf for the path, using the same nomogram, figure 14 , as for the $E$-owf, applying the Es-2000-owf to the left-hand scale and reading the answer on the middle scale. Enter in column $j$. Then modify the procedure in section IV, $1 d(3)$ so that the highest of the thrce values, the $F 2$-owf, the $E$-owf, and the $E s$ owf, columns $l, k, j$, is the owf for the path.

Because of the variable nature of $E s$, and the relative uncertainty with which $E s$ is known, caution should be used in the application of Es-owf, particularly for short paths. While transmission should take place most of the time on Es-owf, fluctuations in Es may at times interrupt service. It is thus often desirable to operate near the owf for the regular layers $(E, F 1, F 2)$ only, without the inclusion of $E s$, although transmission may take place more than 80 percent of the time near the Es-owf.

\section{ABSORPTION, DISTANCE RANGE, AND LOWEST USEFUL HIGH FREQUENCY}

The procedures outlined in the text of this report will give an adequate solution to most of the high-frequency propagation problems that will normally be encountered in the field. If operating frequencies are chosen near the calculated owf prediction in any given case, best possible results should be had, at least in comınunications work.

The use of frequencies too far below the owf will result in weak reception because of increasing ionospheric absorption as the frequency decreases. The factor that limits the usefulness of low field intensities is usually atmospheric noise at the receiving location.
The determination of lowest useful high frequencies is more difficult than the determination of muf and the techniques for their prediction are less far advanced.

The subject of absorption, distance range, and lowest useful high frequency is discussed at length in IRPL Radio Propagation Handbook, Part 1, p. 69-97 (War Dept. TM 11-499, Navy Dept. DNC-13-1), and formulas, graphs, and nomograms for calculation are given there.

Simpler and more accurate techniques are being developed and will be released as soon as the work is completed.

\section{SAMPLE MUF AND OWF CALCULATIONS}

\section{FOR SHORTPATHS}

Required: The muf and owf for transmission between $\mathrm{W}$ ashington, D. C. $\left(39.0^{\circ} \mathrm{N}, 77.5^{\circ} \mathrm{W}\right)$ and Miami, Fla. $\left(25.7^{\circ} \mathrm{N}, 80.5^{\circ} \mathrm{W}\right)$ for average conditions during the month of May 1947.

Solution:

Let the local time used for this problem be GCT ( $Z$ time or that of $0^{\circ}$ longitude).

The midpoint of the path is at approximately $32.5^{\circ} \mathrm{N}, 79.0^{\circ} \mathrm{W}$, and the transmission path length is approximately $1500 \mathrm{~km}$, all in $W$ zone.

The values of $E$ - and F2-layer muf and owf, and also Es-muf and owf for even hours, GCT, as determined by using the procedure given in section IV, are given in table 1 . The final values are presented graphically in figure 16.

Values of owf for the path obtained by the procedure of section IV, 1 for the regular layers only are given in columns $k$ and $l$ of table 1 . The higher of these two values for each even hour is unclerseored and plotted in figure 16 . The resulting graph of owf, for the regular layers only, is shown as a solicl-line curve. It will be noted that $E$-owf is the controlling frequency between the hours of 1200 and 2000.

Values of Es-owf are controlling for hours for which the value in column $j$ exceeds the corresponding underlined value in columns $k$ or $l$. For the month of May, Es-owf is the controlling frequency at the hours of 0800 and 1000 . Values at these hours are used in plotting the dotted line in figure 16.

Figure 16 shows that skip will occur, on the average, during the night hours, if a frequency as high as $15.0 \mathrm{Mc}$ is used. $\Lambda$ frequency as high as $13.5 \mathrm{Mc}$ will not skip, on the average, at any time of day, but its use is not advisable because of $(a)$ the day-to-day variability, causing some probability of skip luring the night hours, and (b) ionospheric absorption during the daytime, which is more pronounced at low frequencies.

A satisfactory plan to insure continuous transmission at all times, over a path like this, involves the use of two frequencies, one for night and one 
for day. Figure 16 shows that a night frequency of $10.1 \mathrm{Mc}$, to be used from 0000 to $1255 \mathrm{GCT}$, and a day frequency of $15.0 \mathrm{Mc}$, to be used from 1255 to $0000 \mathrm{GCT}$, would be satisfactory. The periods of usefulness of these frequencies are shown by the heavy dashed line on figure 16 .

These values of frequency were obtained by including Es-owf in the calculations, and conse- quently, for the reason indicated in the last paragraph of IV, above, some interruptions in service may be expected on the night frequency, since the night frequency, as shown in figure 16 , was chosen above the owf for the regular layers between 0830 and 1045. Better service may possibly be obtained by choosing a lower night frequency, closer to the regular-layer owf.

\section{FOR LONG PATHS}

Required: The muf and owf for transmission between Washington, D. C. $\left(39.0^{\circ} \mathrm{N}, 77.5^{\circ} \mathrm{W}\right)$ and Trieste $\left(45.7^{\circ} \mathrm{N}, 13.8^{\circ} \mathrm{E}\right)$ for average conditions during the month of May 1947.

\section{Solution:}

Let the local time for this problem be GCT ( $Z$ time or that of $0^{\circ}$ longitude).

The path length is approximately $7100 \mathrm{~km}$, and the two $F$-layer control points, $A$ and $B$, respectively, are at approximately $49^{\circ} \mathrm{N}, 56.5^{\circ} \mathrm{W}$, and $52^{\circ} \mathrm{N}, 12.5^{\circ} \mathrm{W}$. These are, respectively, in the $W$ zone and the $I$ zone, as shown on the inap, figure 1. The two E-layer and $E s$ control points, $A^{\prime}$ and $B^{\prime}$, respectively, are located at approximately $44^{\circ} \mathrm{N}, 68.5^{\circ} \mathrm{W}$, and $49.5^{\circ} \mathrm{N}, 1.5^{\circ} \mathrm{E}$. These are in the $W$ and $I$ zones, respectively.

The values of muf and owf over this transmission path, as determined by the procedure in section IV, are given in table 2 for even hours, GCT. Provision has been made in the computation of this table for the inclusion of the effects of $E s$. The final figures are shown graphically in figure 17 .

Figure 17 shows that skip will occur, on the average, during the night hours if a frequency as high as $14.0 \mathrm{Mc}$ is used, although higher frequencies may be used during much of the twenty-four hours.
A good, practical arrangement to insure continuous transmission at all times is to select three frequencies in a manner similar to that suggested in the preceding problem. A frequency of 10.3 Mc may be used from 0250 to $0935 \mathrm{GCT}$, a frequency of $18.0 \mathrm{Mc}$ may be used from 1400 to $0110 \mathrm{GCT}$, and a transition frequency of $14.0 \mathrm{Mc}$ may be used from 0935 to $1400 \mathrm{GCT}$, and from 0110 to $0250 \mathrm{GCT}$.

By inspection of the absorption chart and the noise map (figs. 84 and 119, of the IRPL Radio Propagation Handbook, Part 1, War Dept. TM 11-499, Navy Dept. DNC-13-1), it may be seen that considerations of the lowest useful high frequency over this path may be of considerable importance in selecting frequencies for use. Consequently, in cases of transmission failure on the frequencies here recommended, particularly in the case of the transition frequency, changing the frequency to a value slightly under the muf for the path may be advisable.

The bearing of Trieste from Washington is approximately $51^{\circ}$, and that of Washington from Trieste is approximately $299^{\circ}$, both determined by the nomogram of figure 4 . 


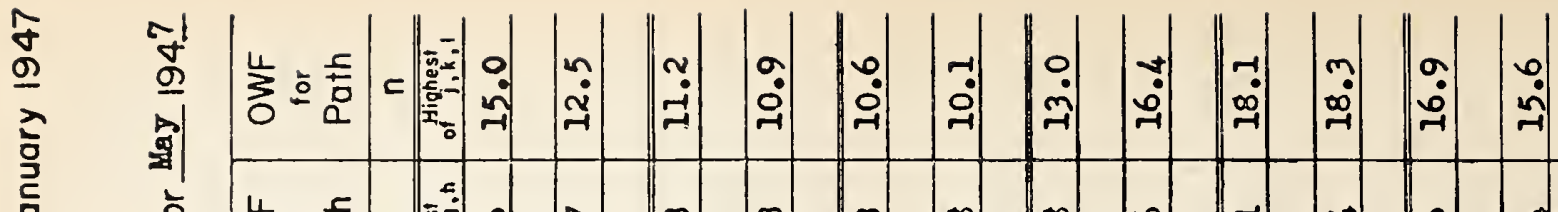

한.

N $\quad \frac{8}{7}$

崖

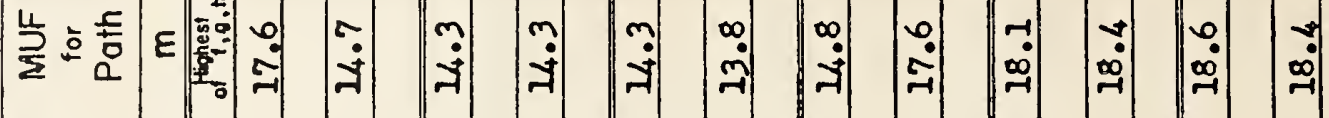

iv

出

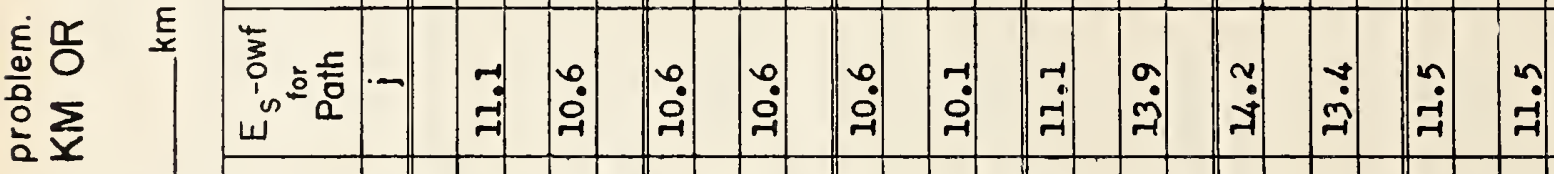

응

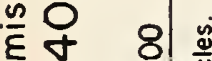

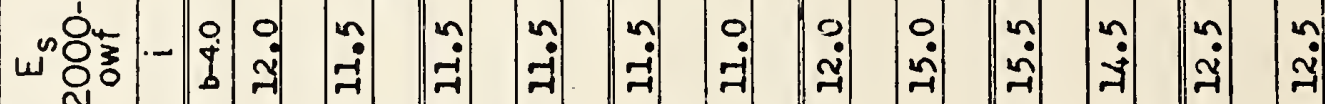
象

足

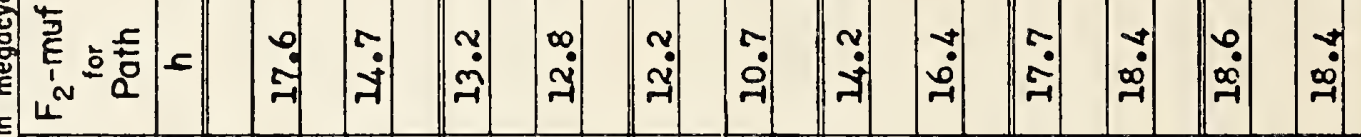
至造

t品

空

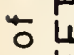

. $\frac{\mathrm{L}}{\mathrm{T}}$

(

i 잉

$-3$

㟒嵌

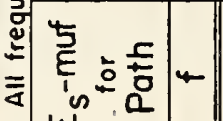

?

w

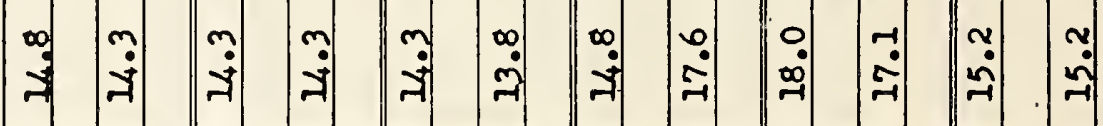

$\vdash 0$

$\stackrel{4}{\Sigma}$

岁

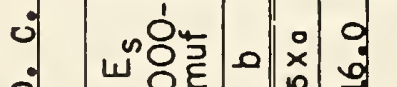

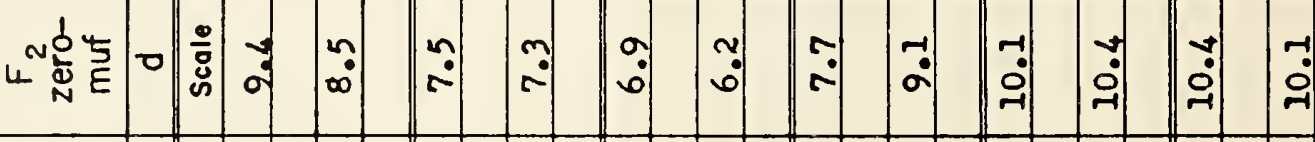

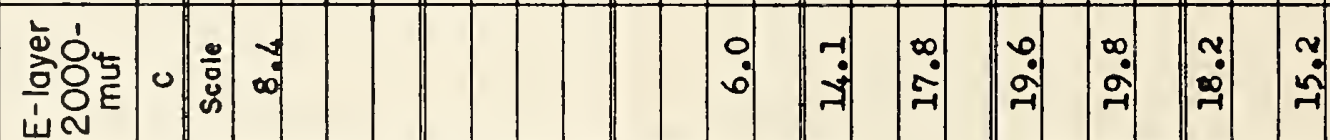

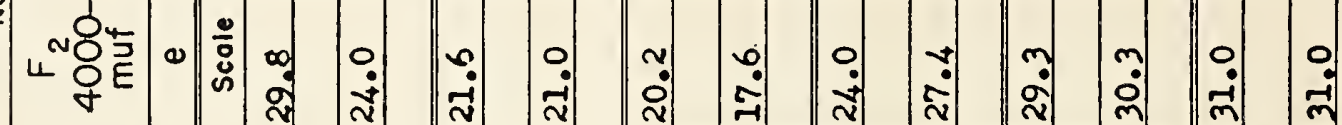
(रb 
告 岂竞要

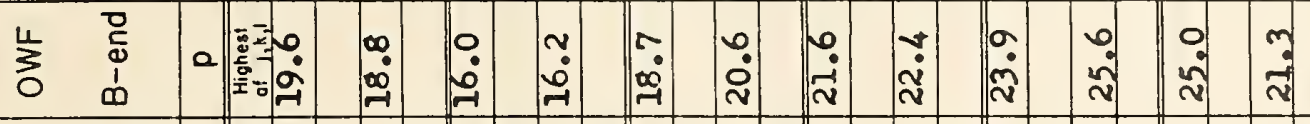

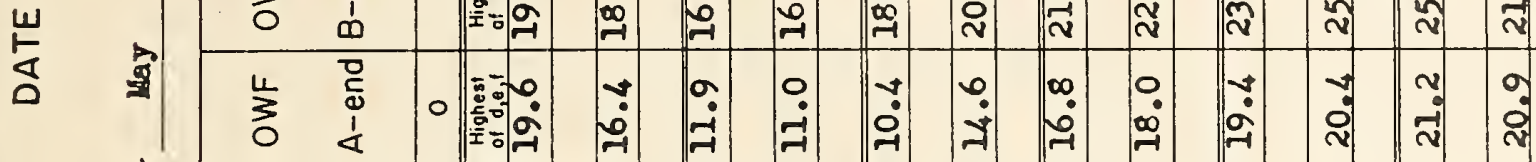
के

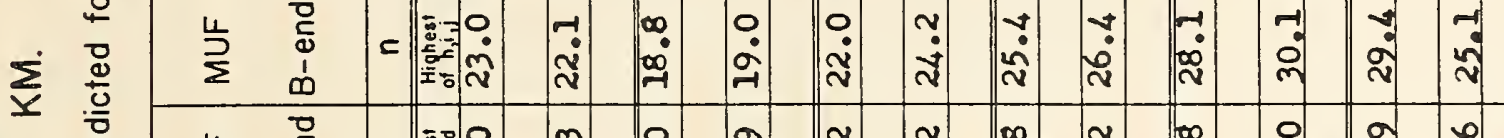

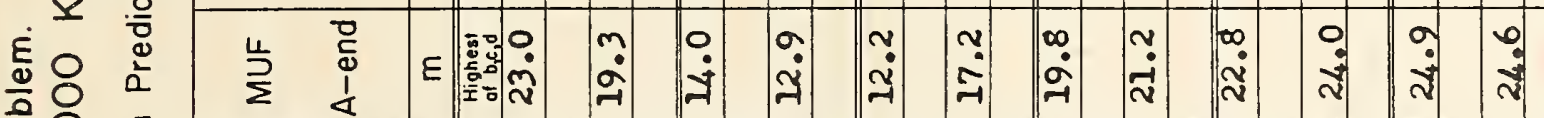

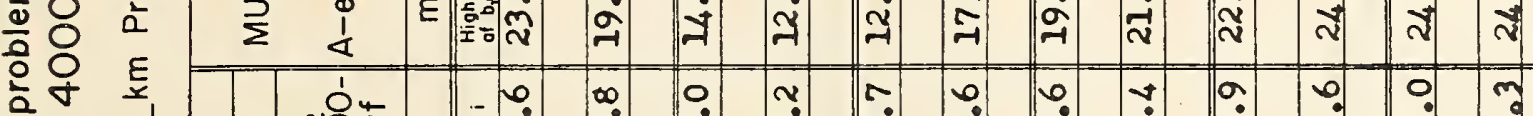

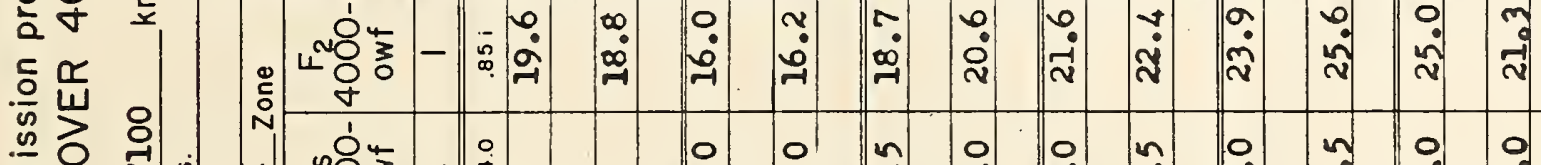

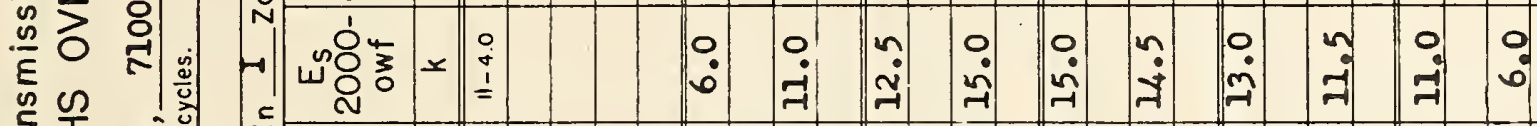

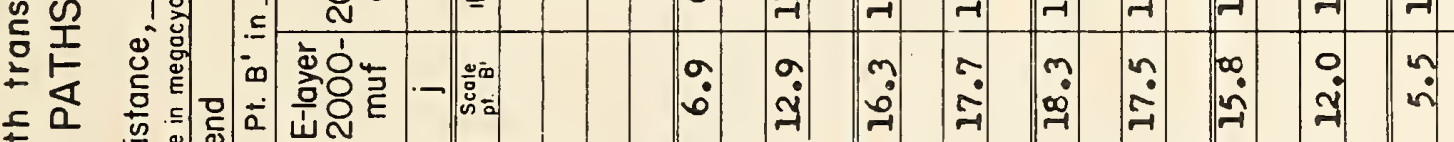

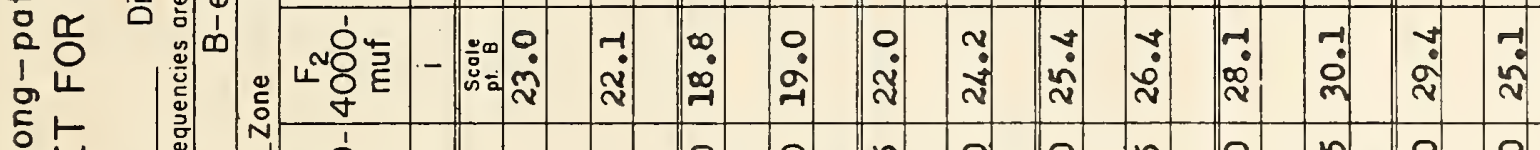

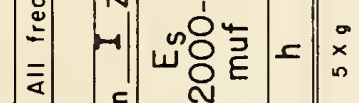

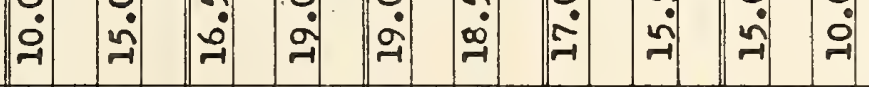
言空

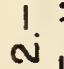
崖

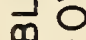

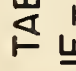

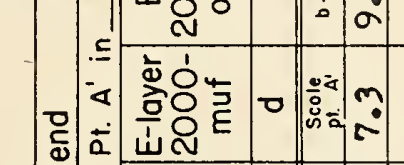

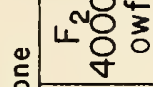
我路:

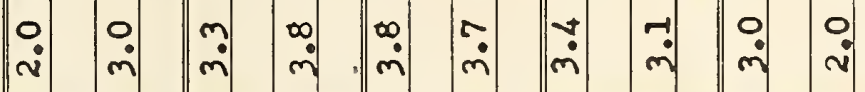
- 4 这

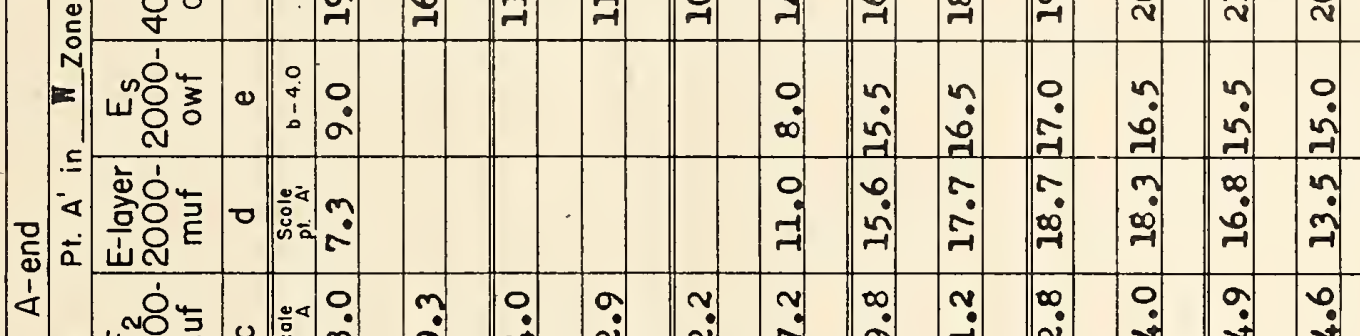

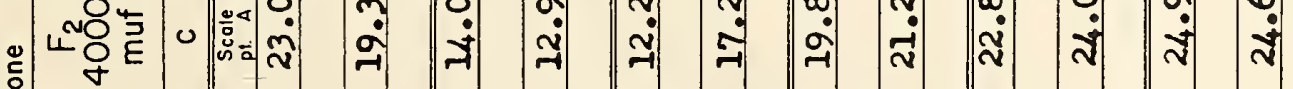

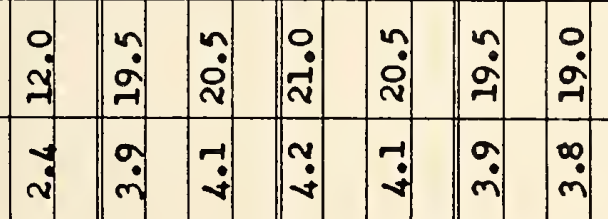

总 


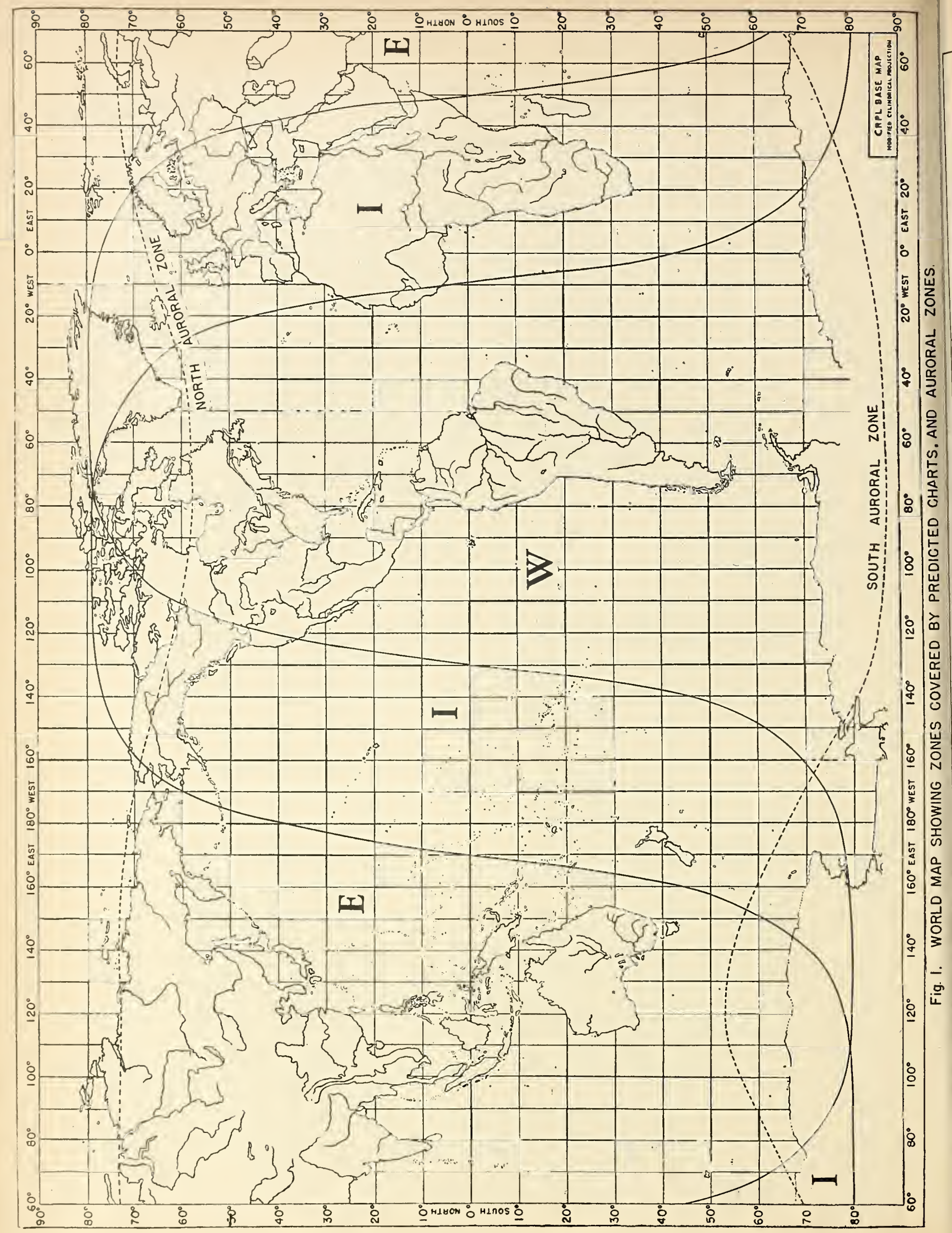




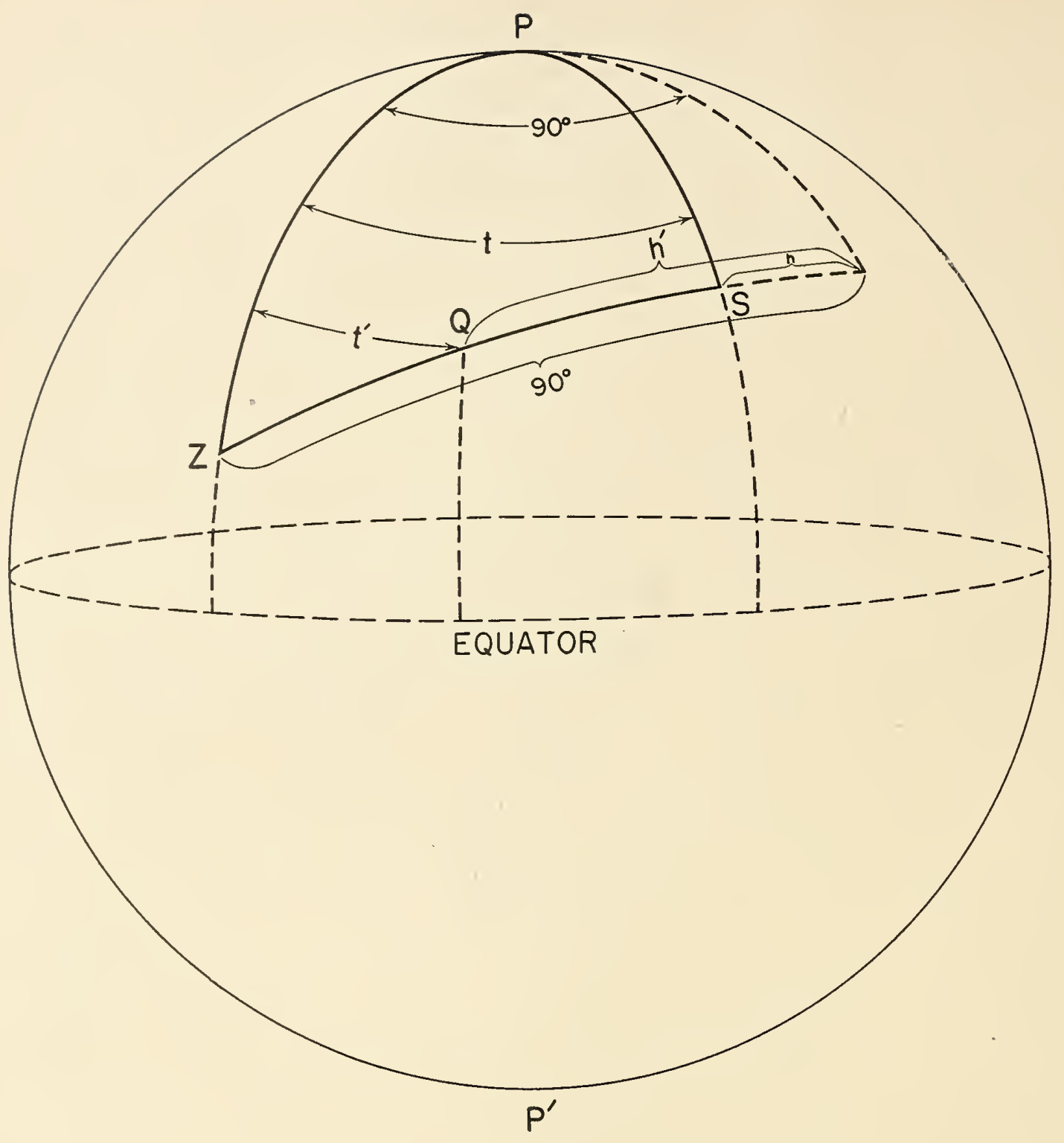

Fig. 3. DIAGRAM OF TRANSMISSION PATH AUXILIARY TO EXPLANATION OF USE OF DISTANCE - BEARING NOMOGRAM, FIG. 4. 


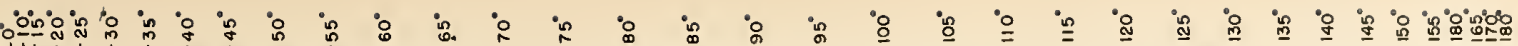

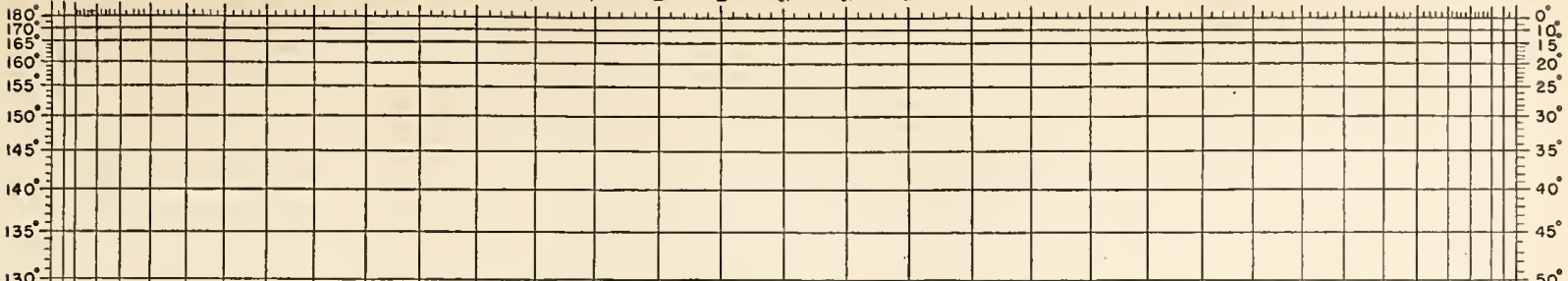

$125^{\circ}$

$120^{\circ}$

$115^{\circ}=$

$110^{\circ}=$

$105^{\circ}=$

$100^{\circ}$

$95^{\circ}=$

$90^{\circ}=-$

$80^{\circ}=$

$75^{\circ}=$

$70^{\circ}=$

$65^{\circ}$

$60^{\circ}=$

$50^{\circ}=$

$45^{\circ}$

$40^{\circ}=$

$35^{\circ}$ 争

$25^{\circ}$

$20^{\circ}$

잉ำ

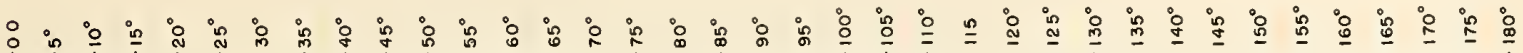
أسلسلس

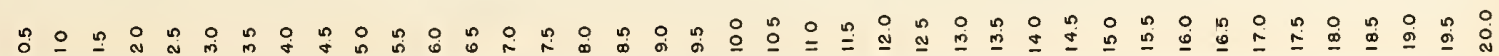

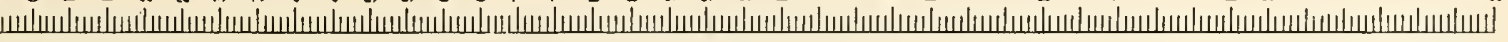

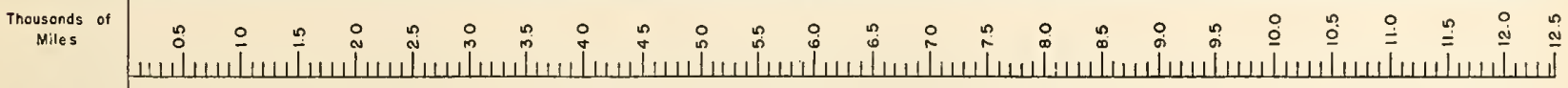

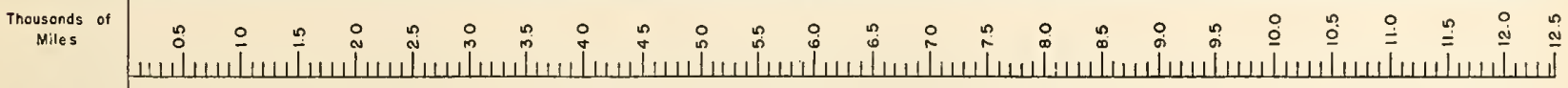

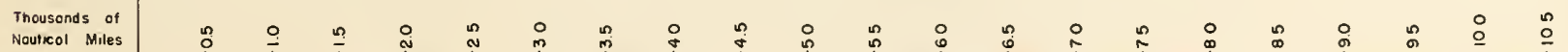

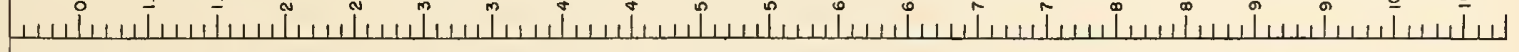

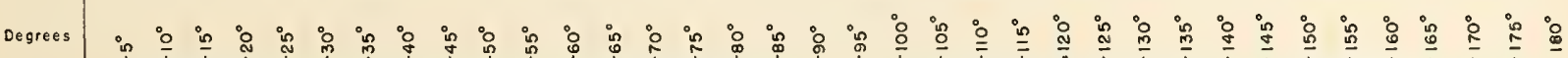

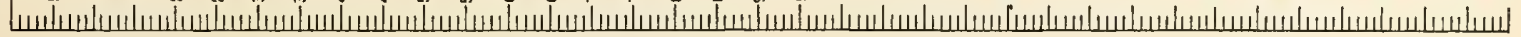

Fig. 4. NOMOGRAM (AFTER D'OCAGNE) FOR OBTAINING GREAT-CIRCLE DISTANCES, BEARINGS, LATITUDE AND LONGITUDE OF TRANSMISSION CONTROL POINTS, SOLAR ZENITH ANGLES.

CONVERSION SCALE FOR VARIOUS DISTANCE UNITS. 


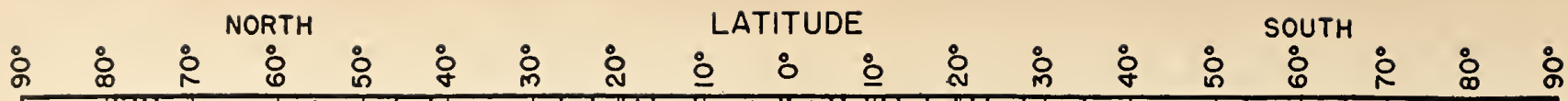

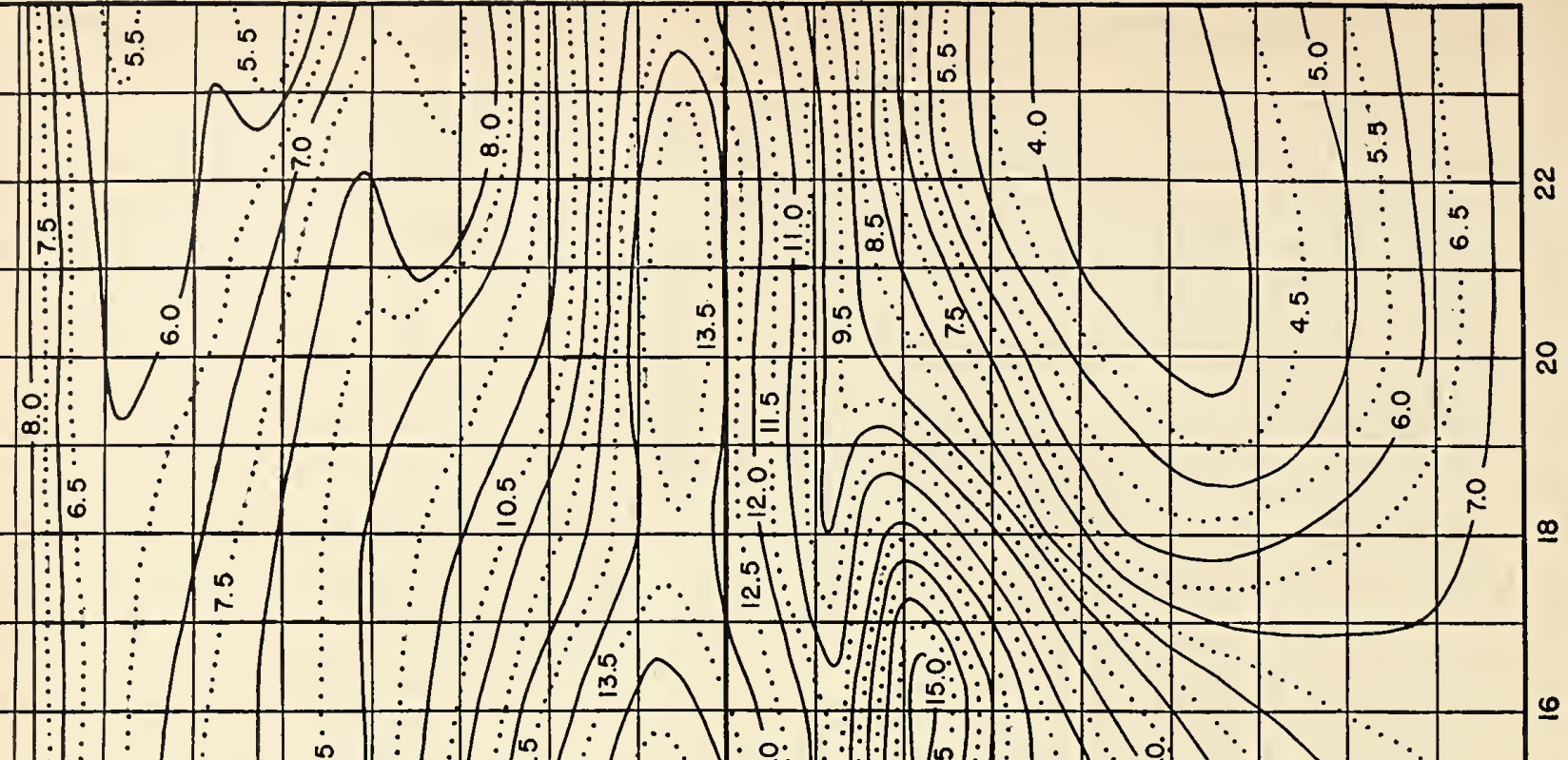
客

$::$

$:: 1: 1:$

: : : : : : : :

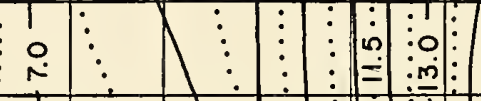

::::::::: : :

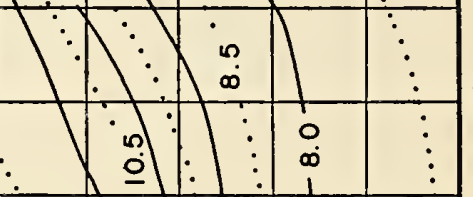

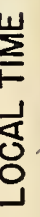

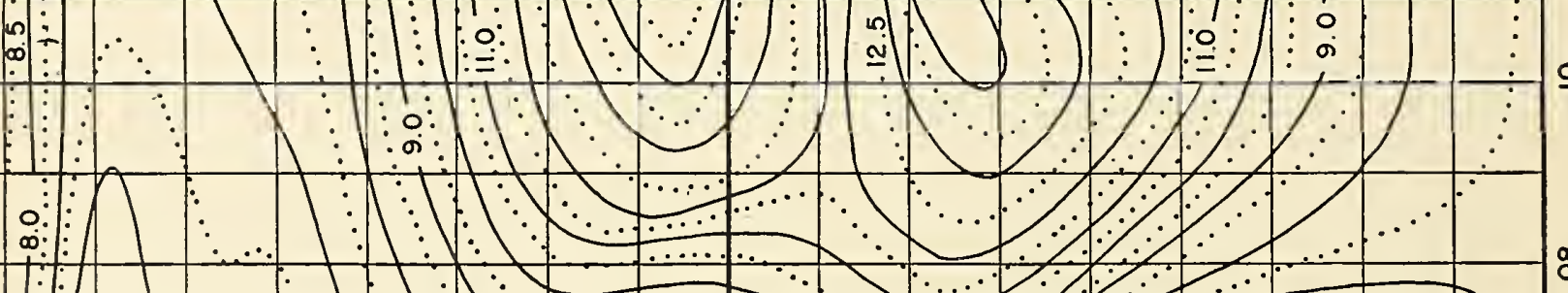
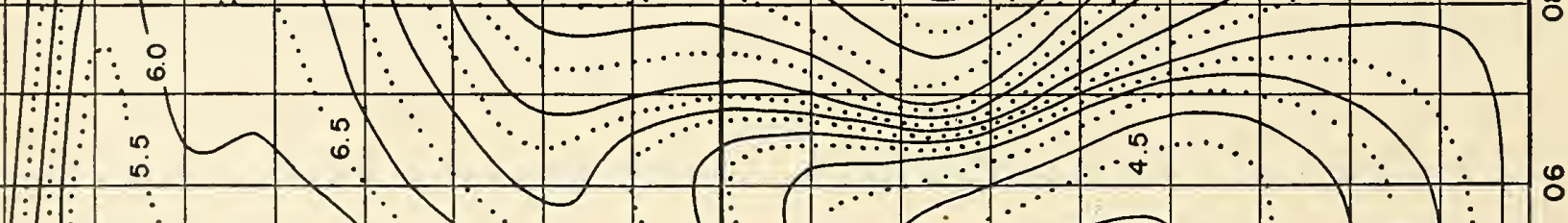

.
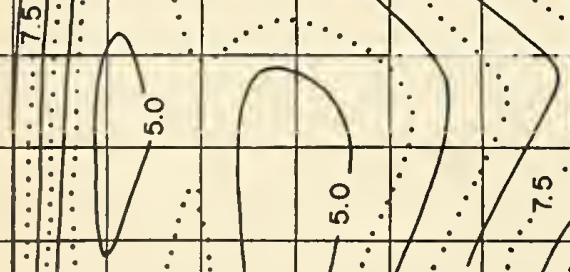

n)
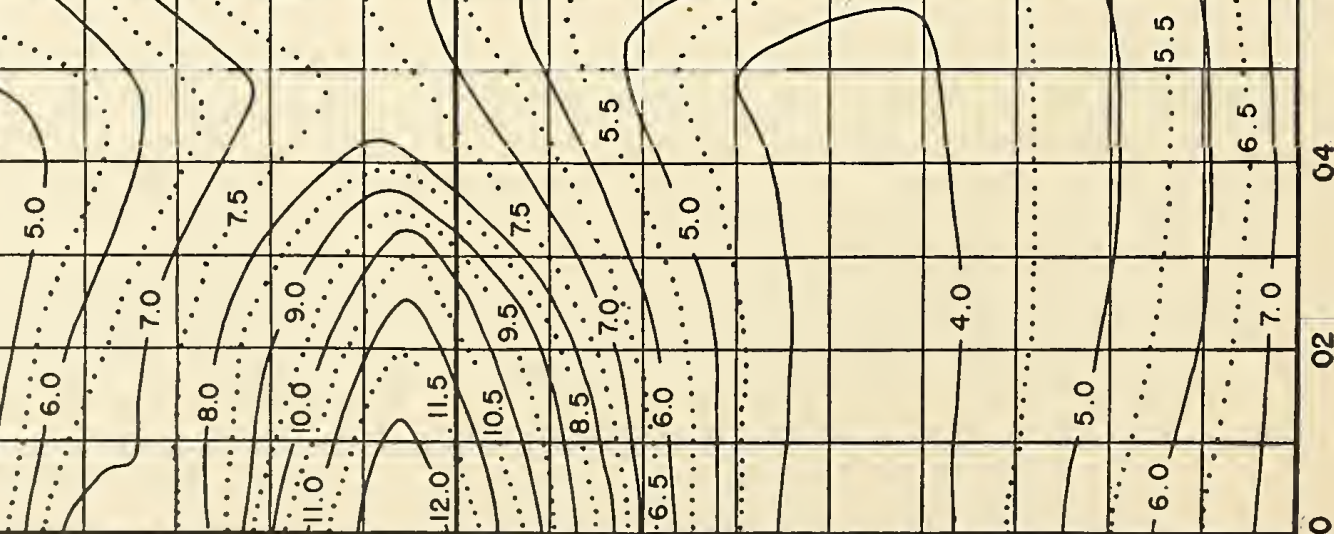

$0: 0: 0: 0$

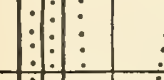

Fig. 5. $F_{2}$ ZERO-MUF, IN MC, W ZONE, PREDIGTED FOR MAY 1947 


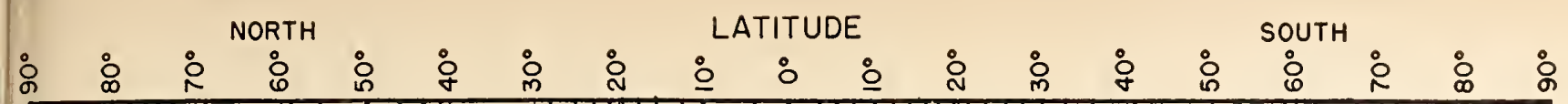

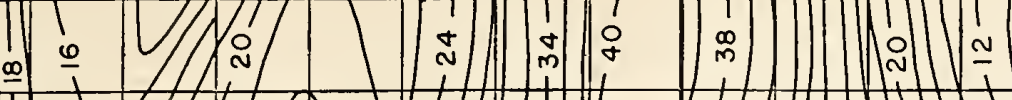

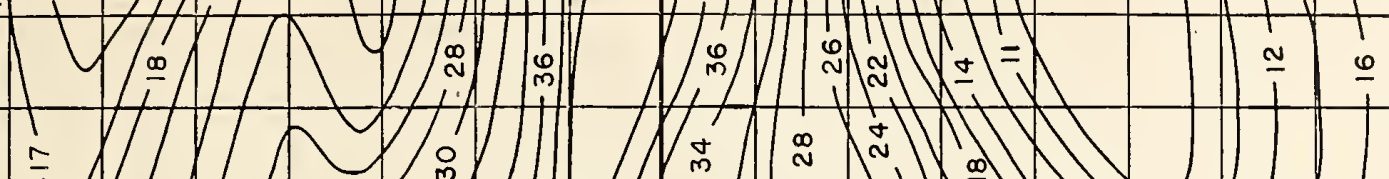

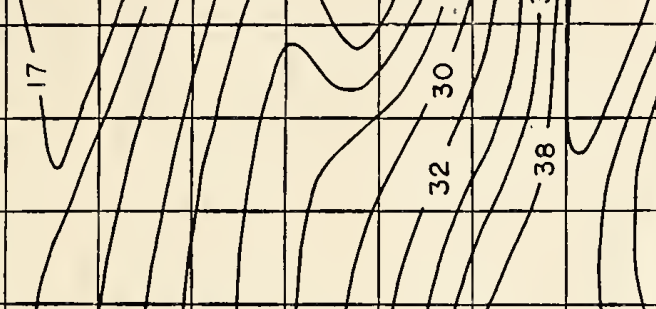

- $1 \begin{array}{llll}1 & \\ 0 \\ 0 \\ N\end{array}$

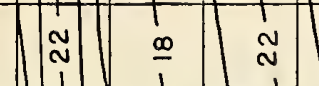

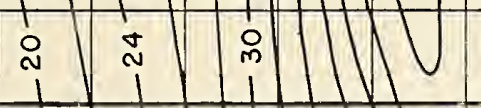

$\left|\begin{array}{l}\omega \\ \stackrel{\omega}{N}\end{array}\right| \mid \underline{\infty}$

In
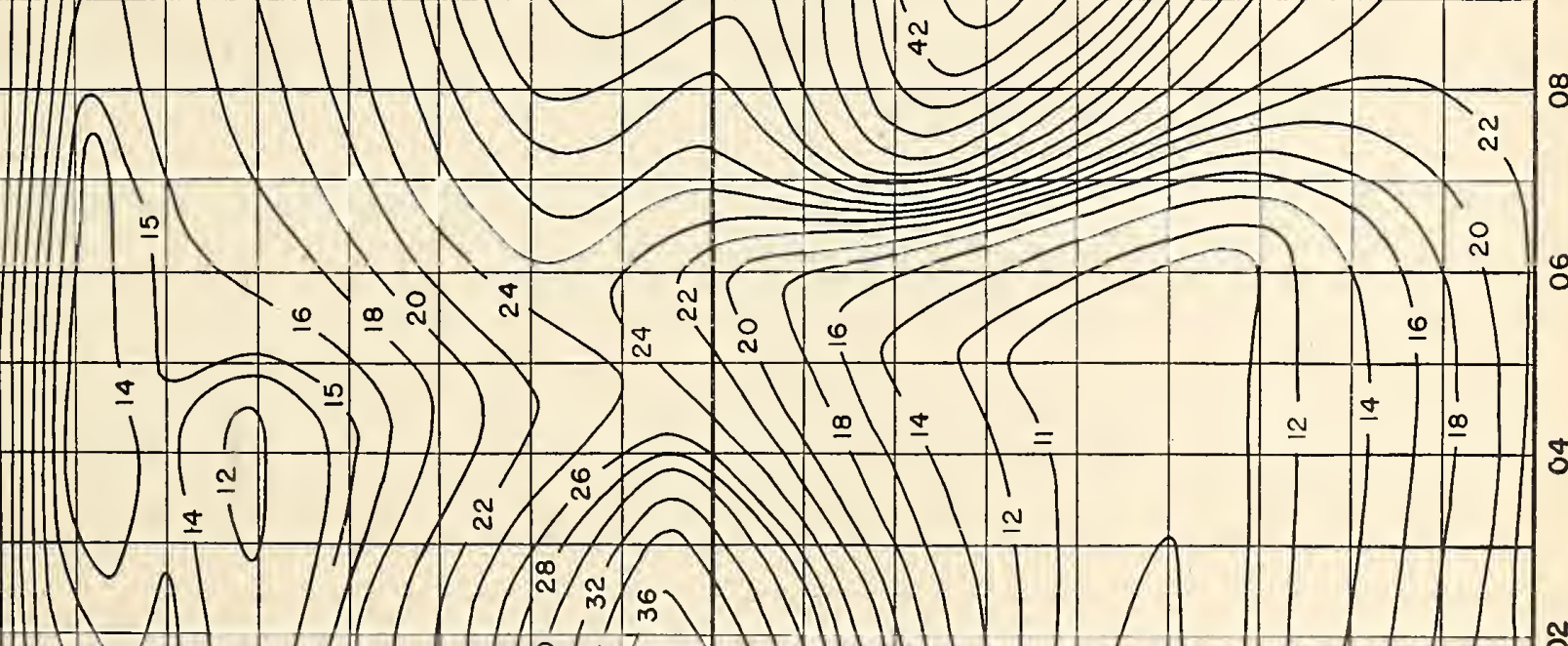

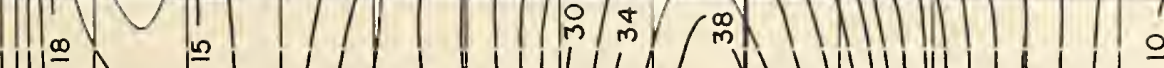

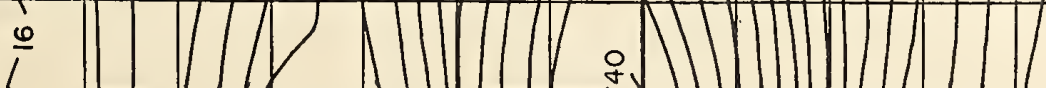




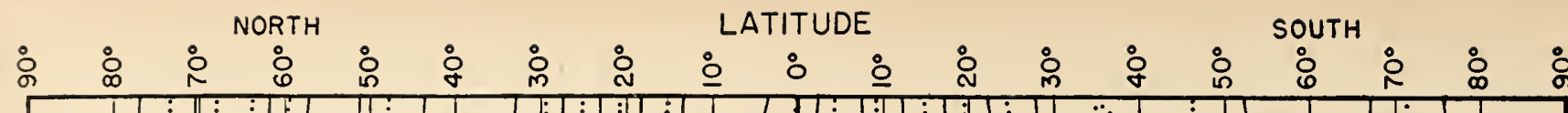

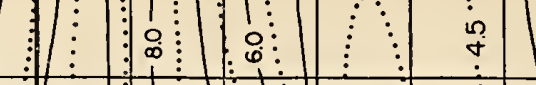

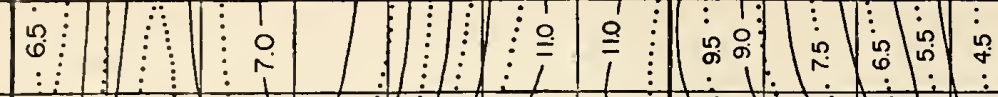
(1)

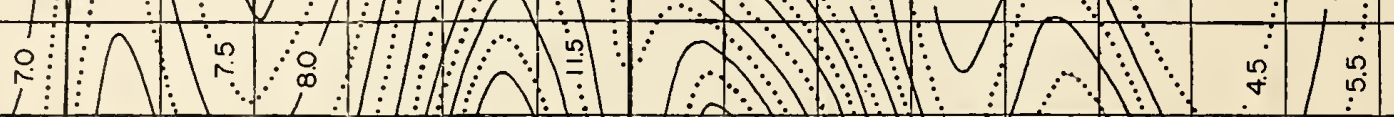

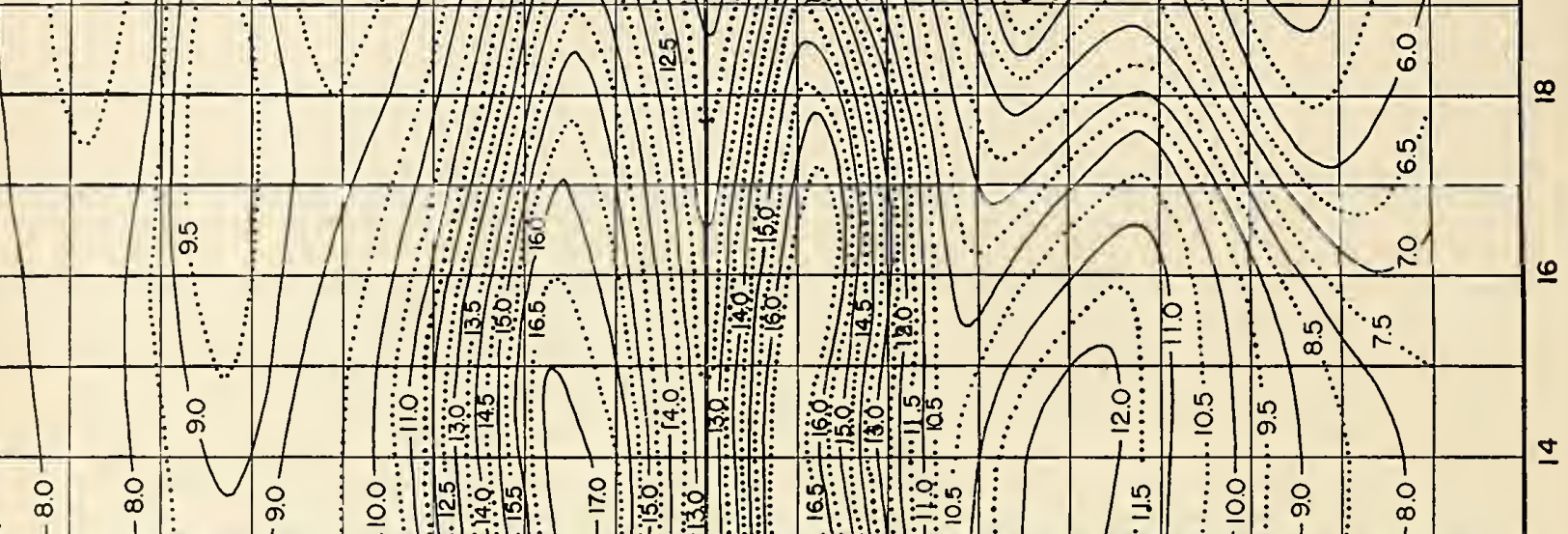

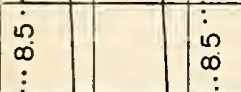

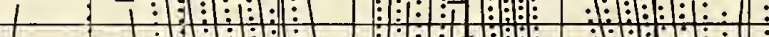




\section{NORTH LATITUDE}

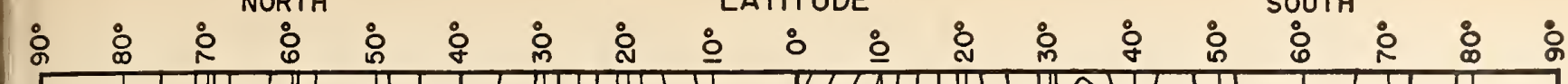

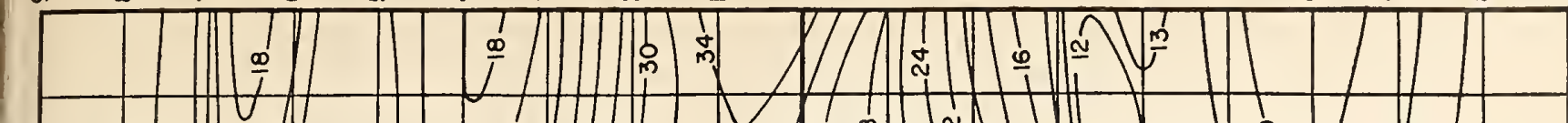

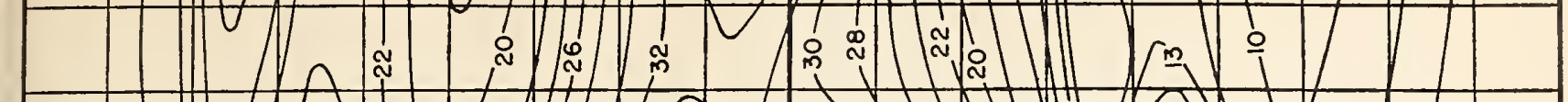

(1) i

幽

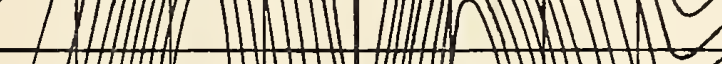

$\underset{\sim}{\sim}$

:

$:$ M

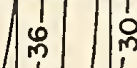

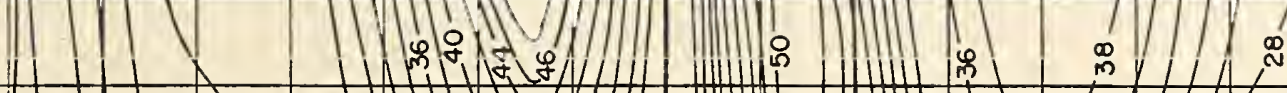

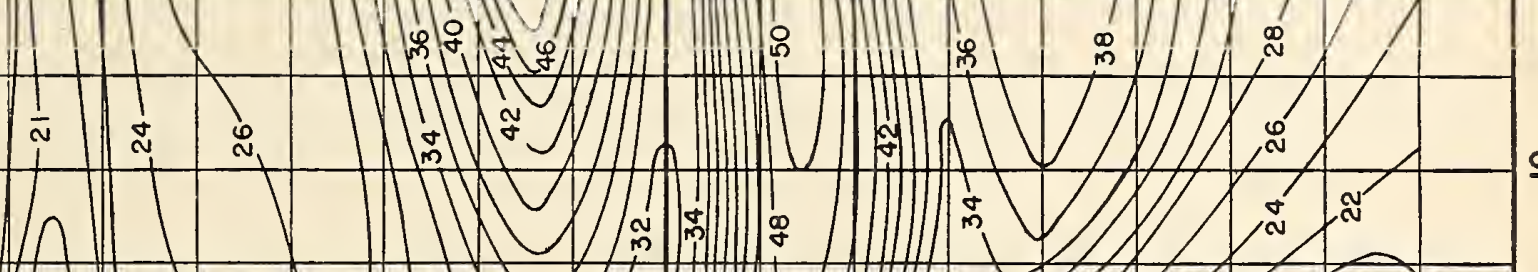
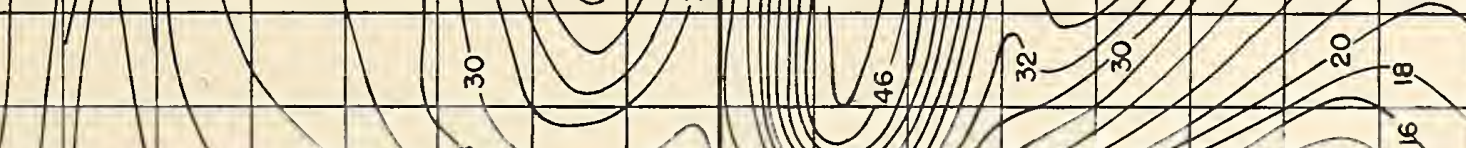

\&

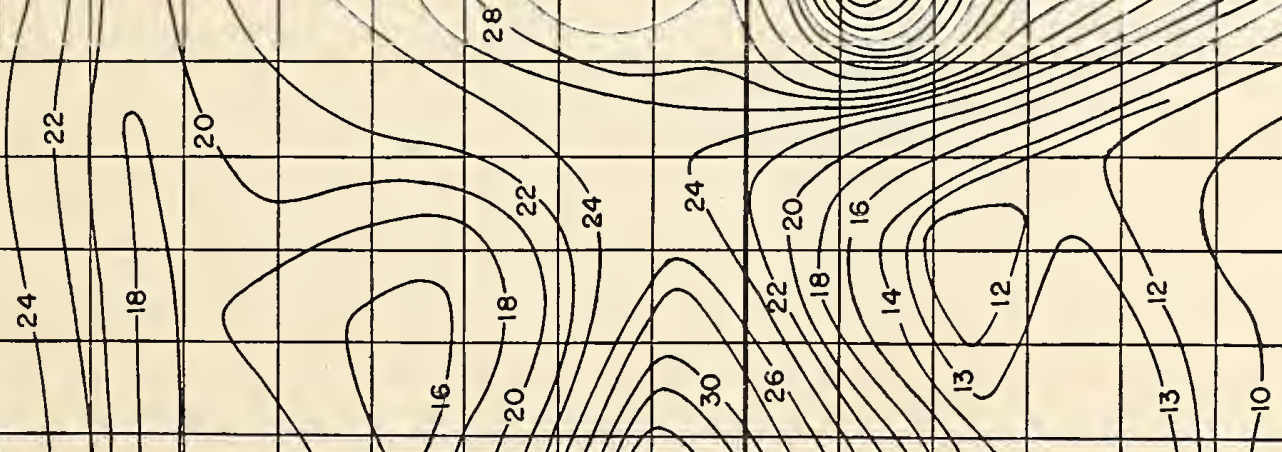

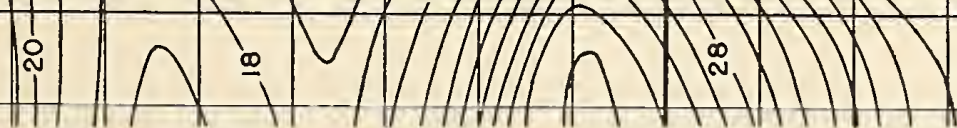

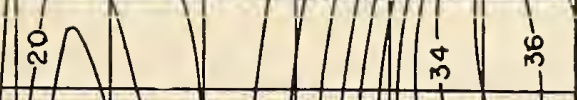

Fig. 8. 空 


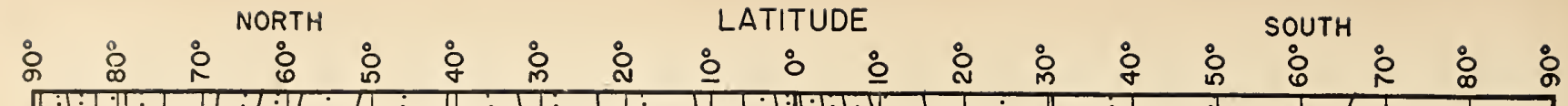

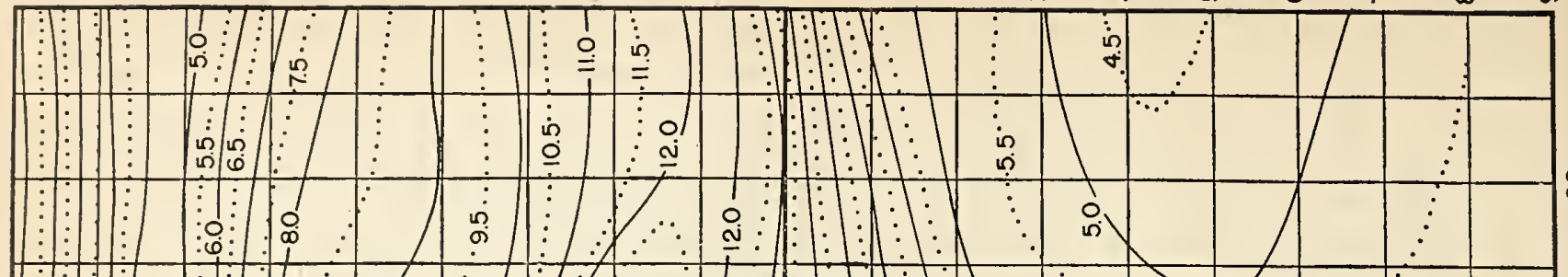

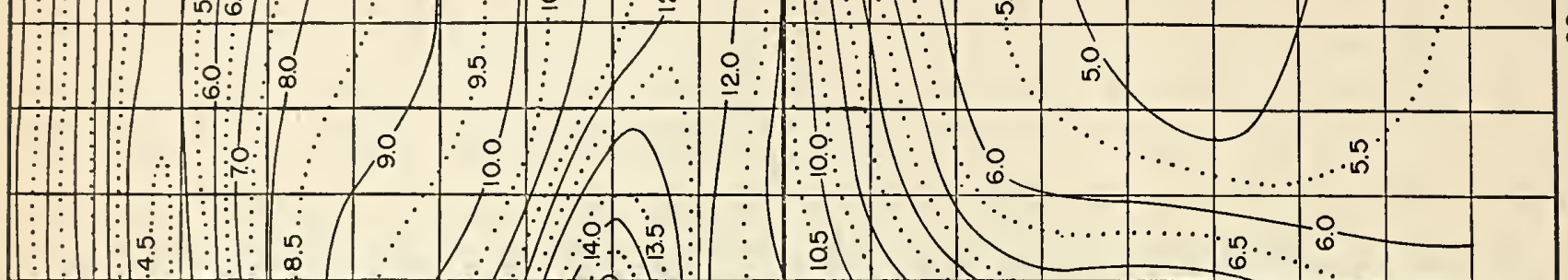

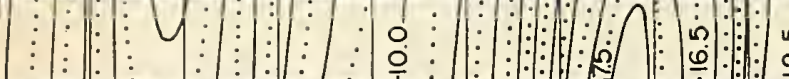
:

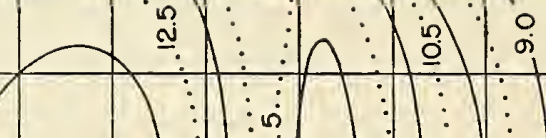

$\vdots \vdots$ in $\vdots \vdots \vdots \vdots \vdots \vdots \vdots 0)$

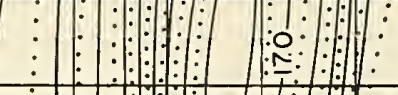

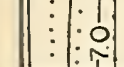

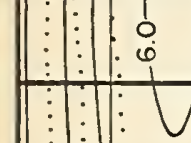

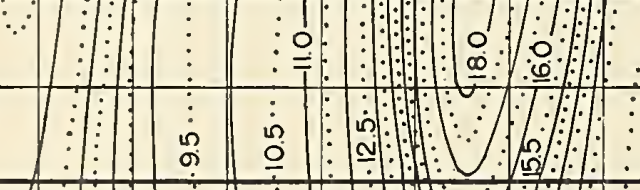

$\vdots \vdots \vdots:$ :

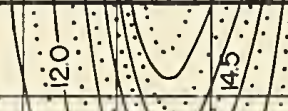

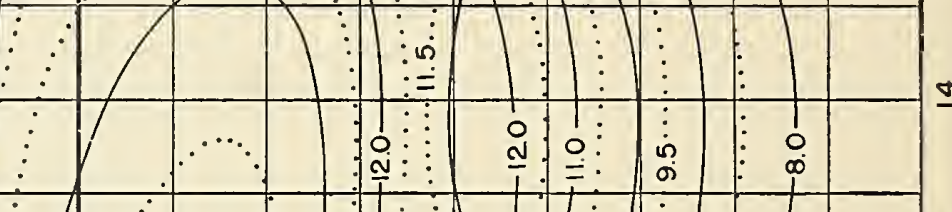

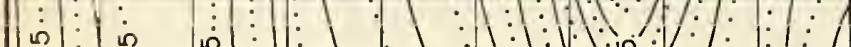
$\stackrel{m}{m}$

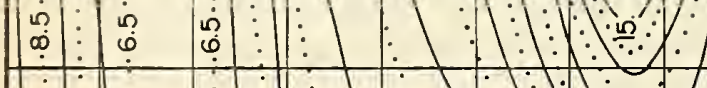

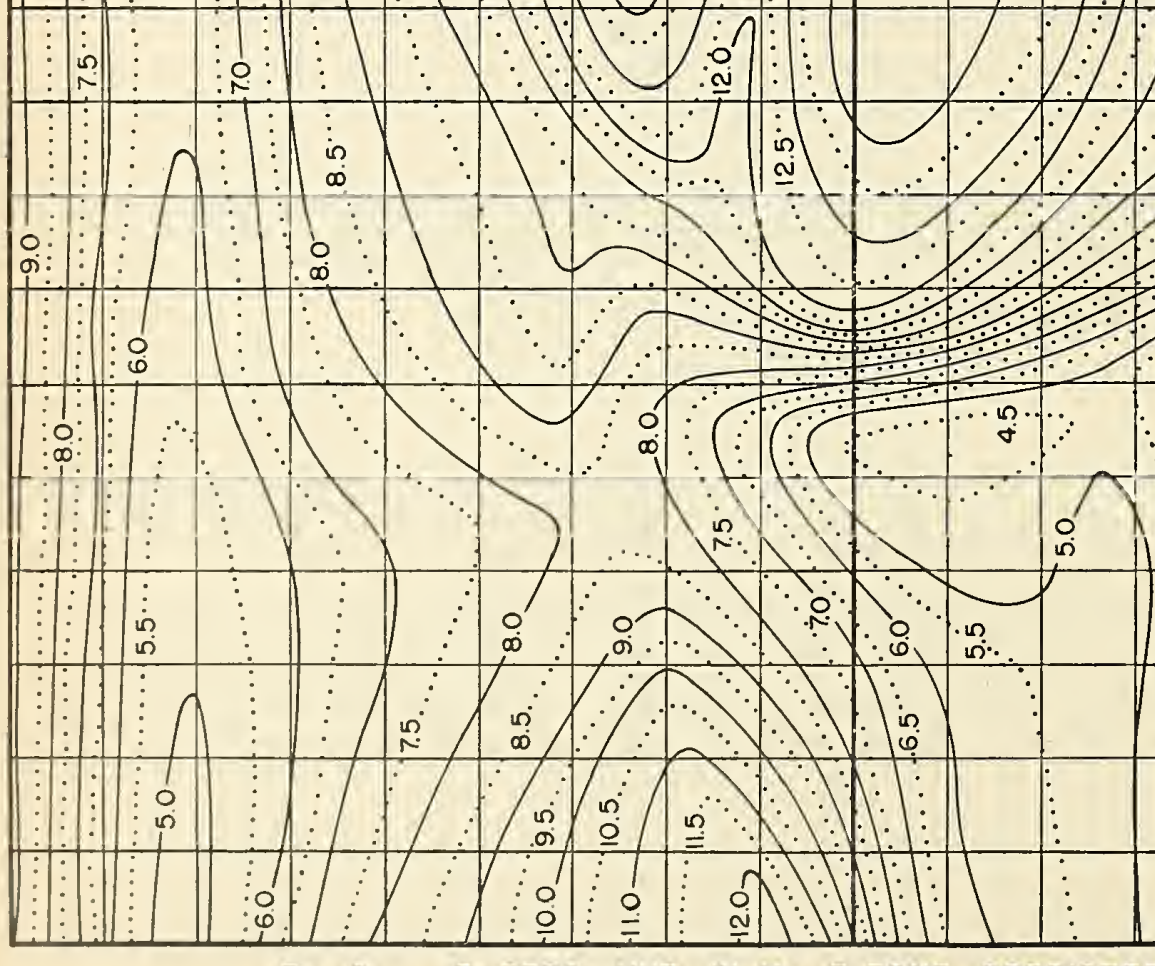

Fig. 9. $F_{2}$ ZERO-MUF, IN MC, E ZONE, PREDICTED FOR MAY 1947 


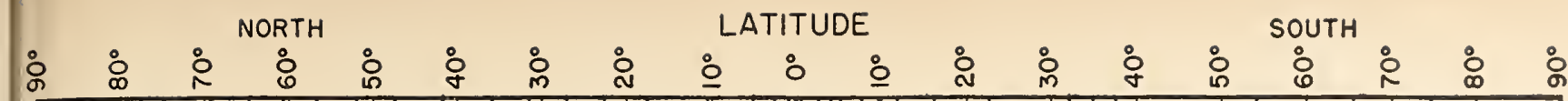
(1) (1) V

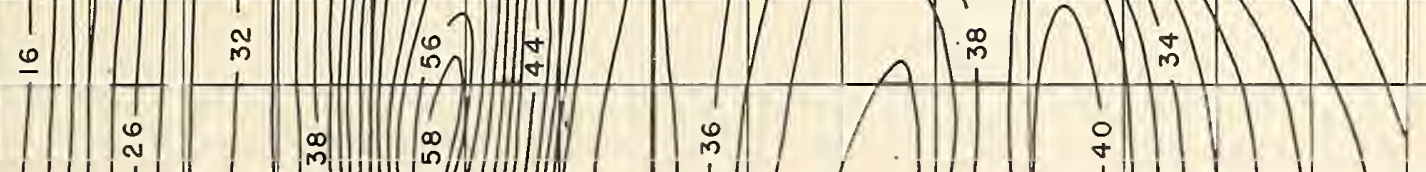
年

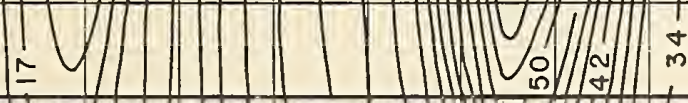

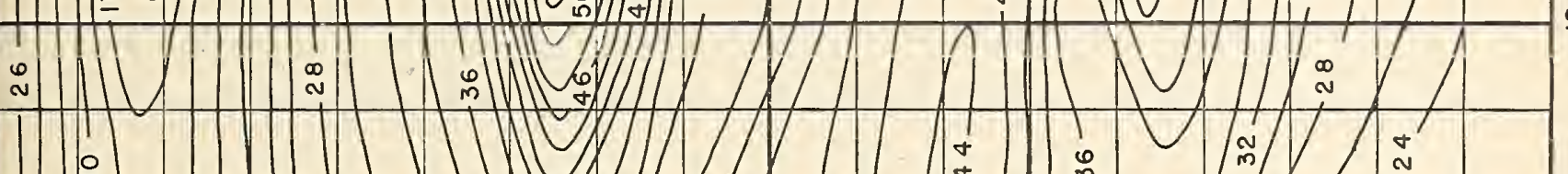

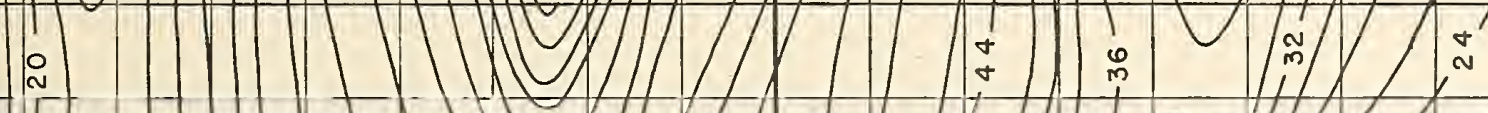

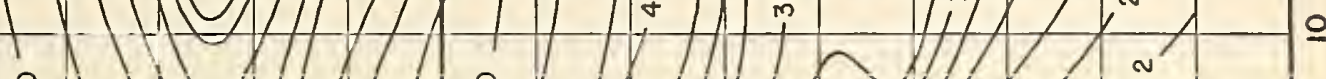
(1)

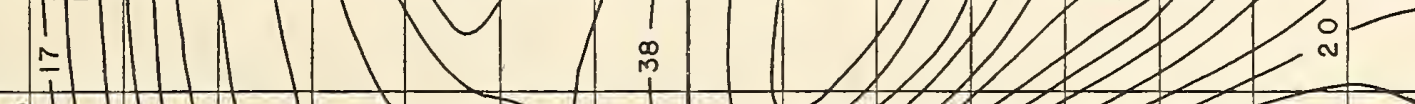

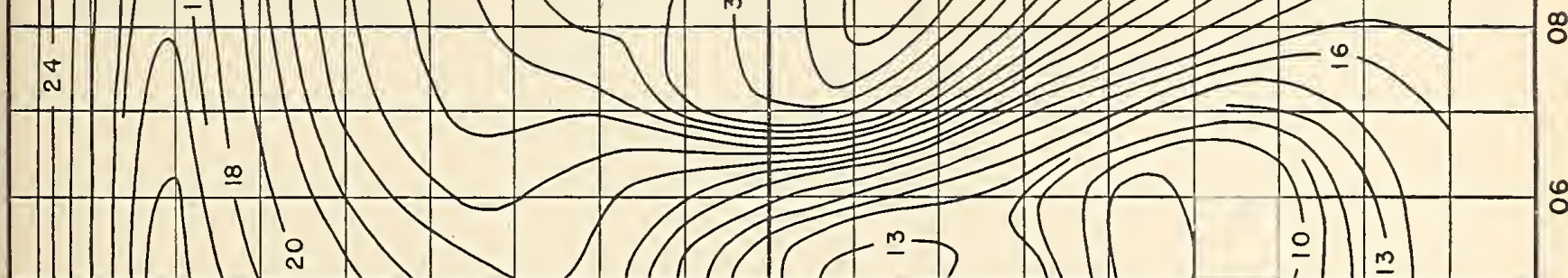
(1)

Fig. 10. $F_{2}$ 4000-MUF, IN MC, E ZONE, PREDICTED FOR MAY 1947 
NORTH LATITUDE

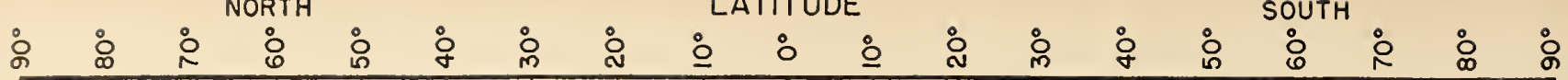

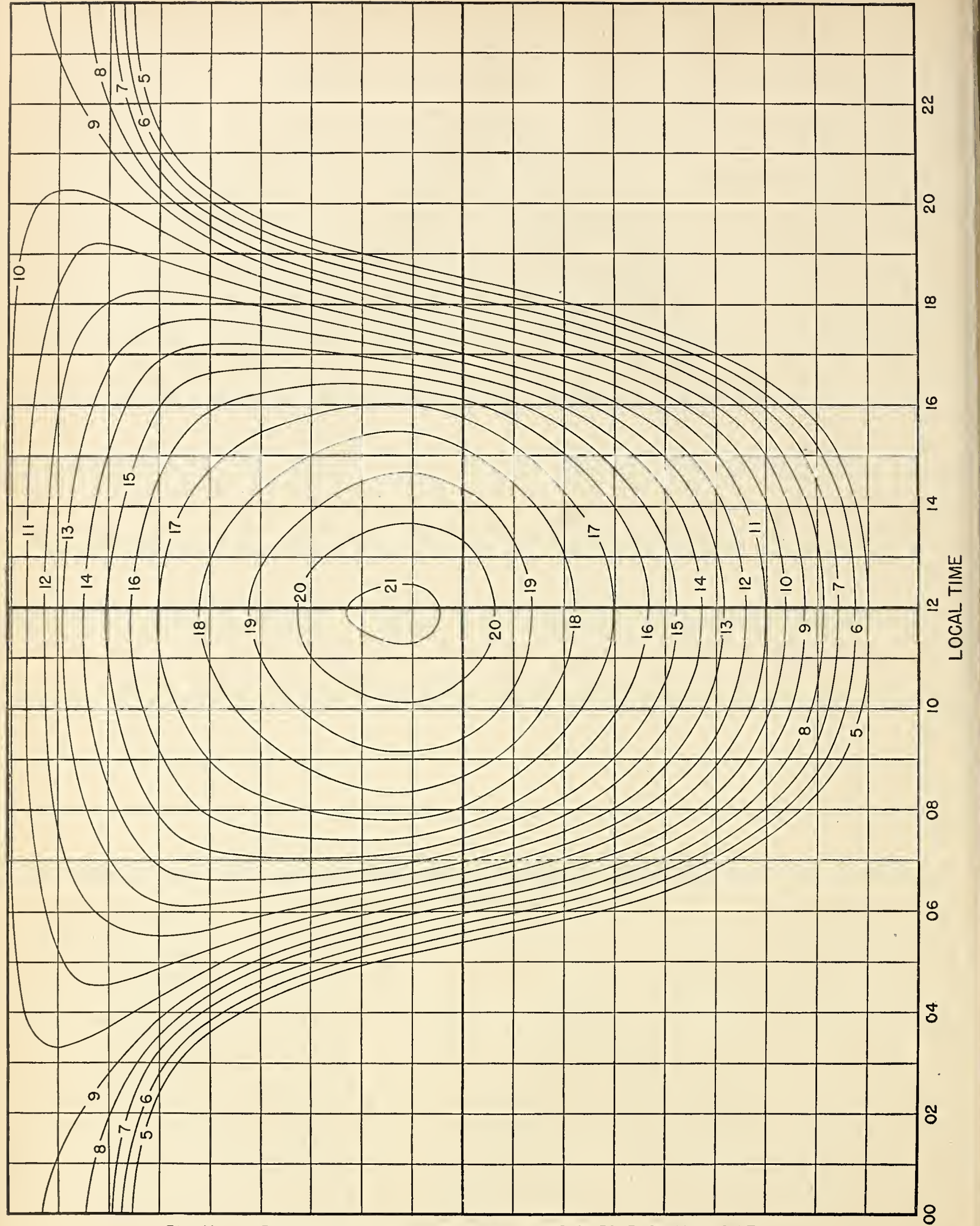




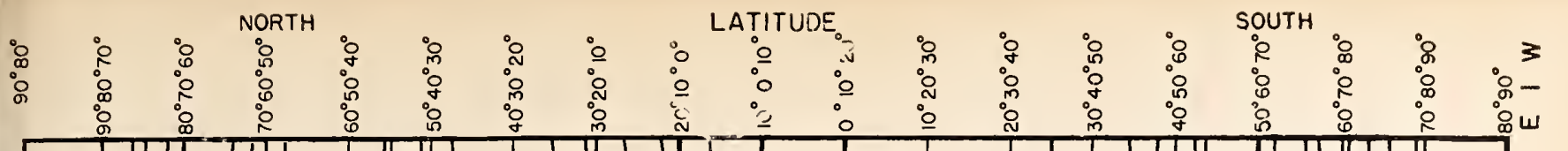

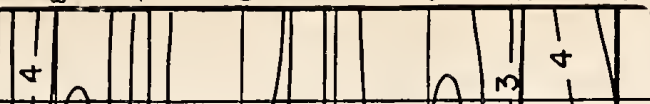
v

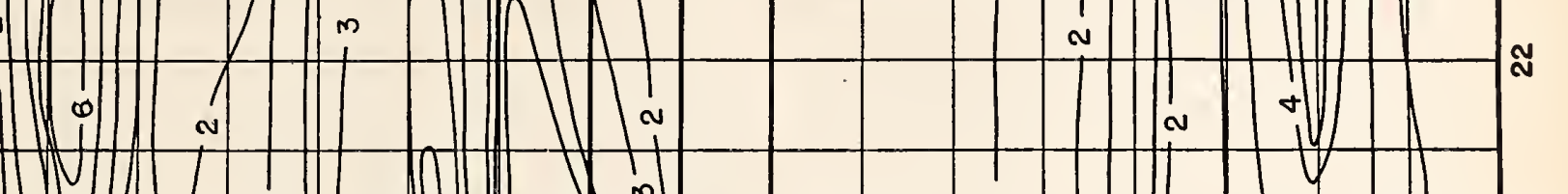
(n) 10 .

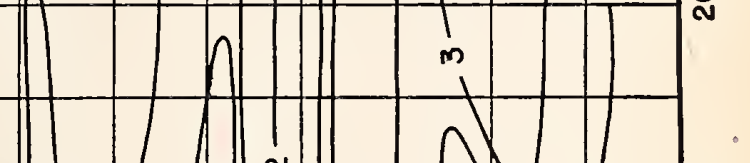
10 (1) A 0.10 1000 . 4 (1) $1+\mid$ $m$ m D $\sim$ N || \begin{tabular}{l}
\hline \\
\hline
\end{tabular}

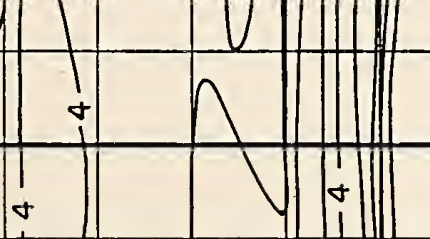
$\int_{6} 10$ $\underbrace{n}_{n}$

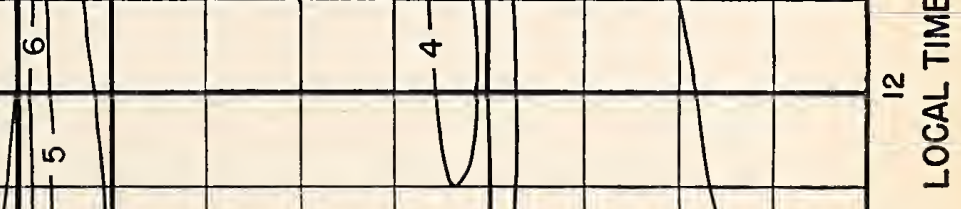
(n) UA

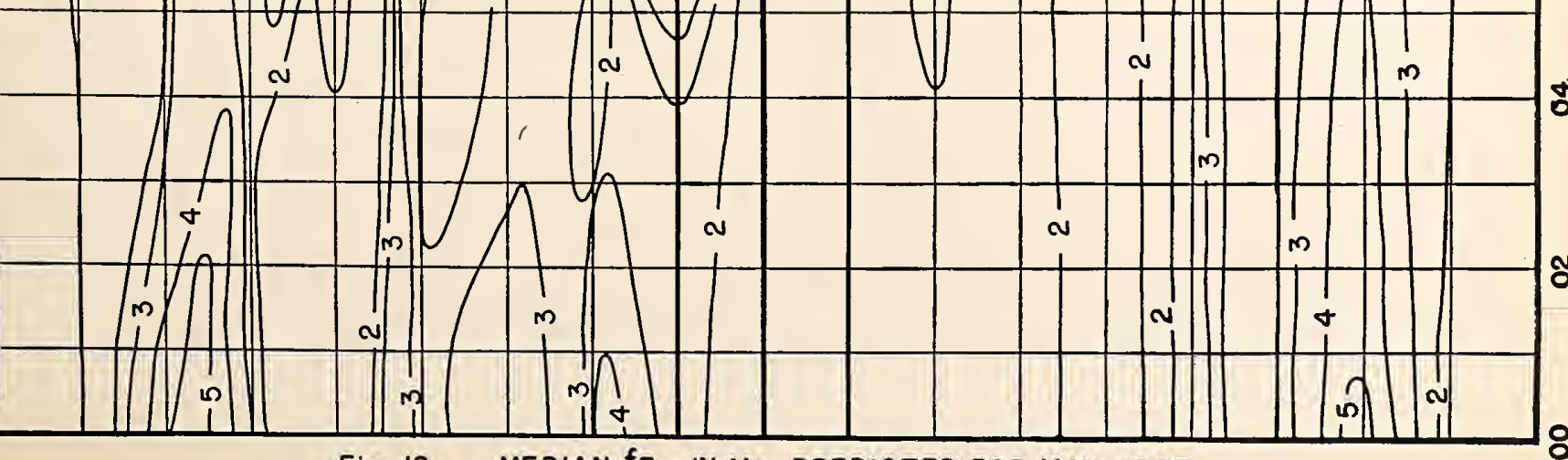


FOR VALUES OF MUF GREATER THAN 35 MC, MULTIPLY ALL MUF AND OWF SCALES BY 2

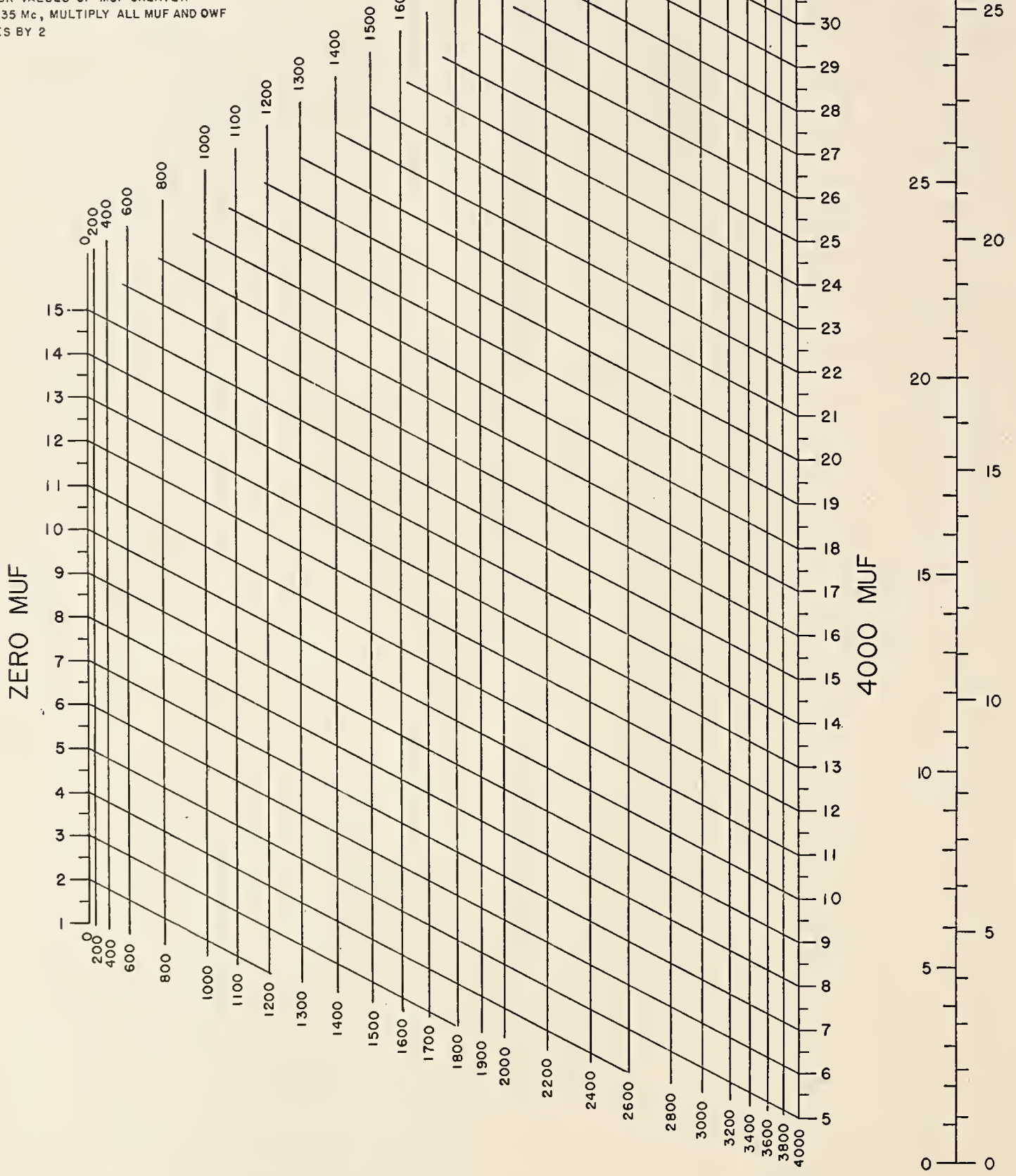

FIG.13. NOMOGRAM FOR TRANSFORMING $F_{2}$-ZERO-MUF AND $F_{2}-4000$-MUF TO EQUIVALENT MAXIMUM USABLE FREQUENCIES AT INTERMEDIATE TRANSMISSION DISTANCES; CONVERSION SCALE FOR OBTAINING OPTIMUM WORKING FREQUENCIES. 


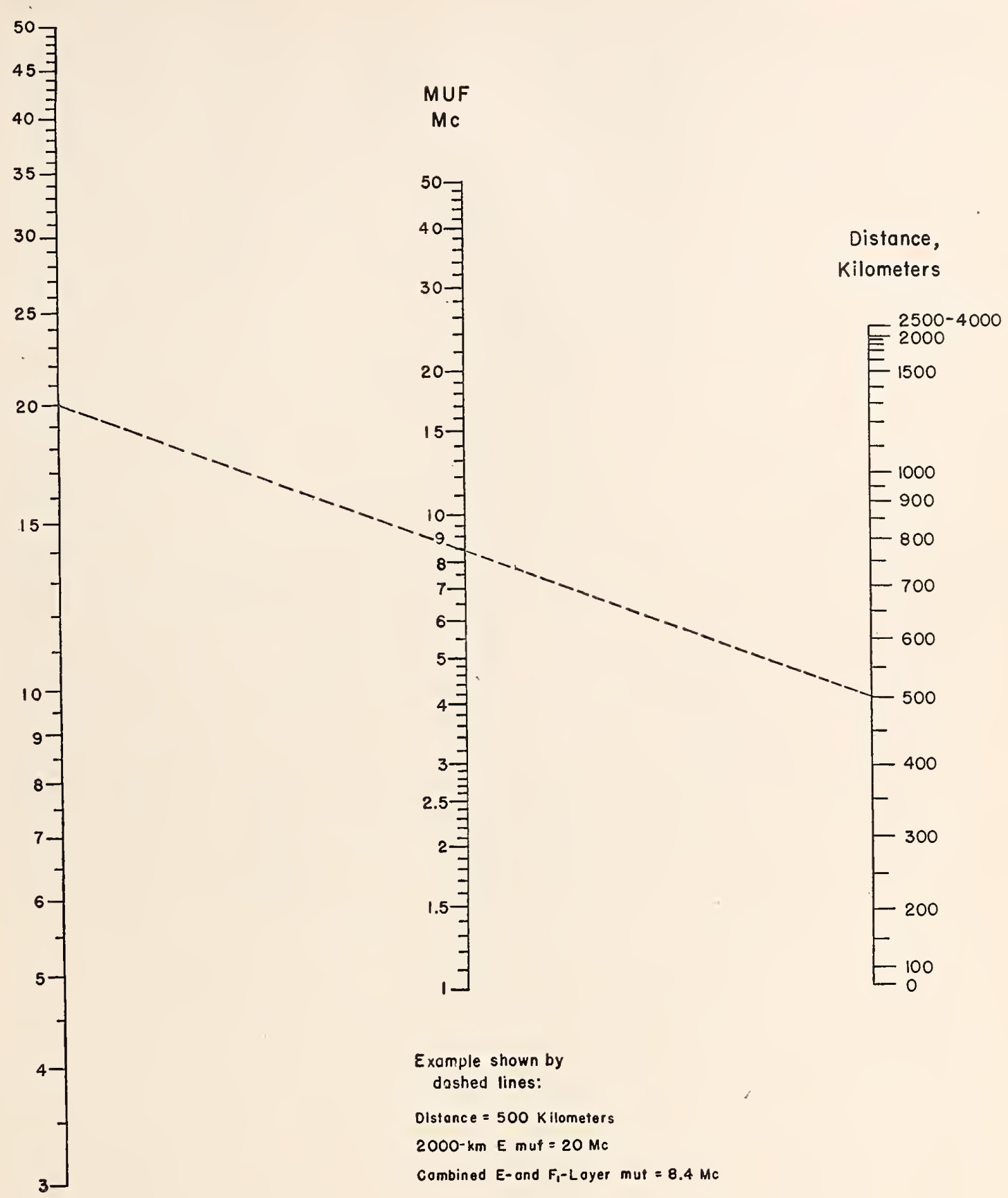

FI5. 14. NOMOGRAM FOR TRANSFORMING E-LAYER 2000-MUF TO EQUIVALENT MAXIMUM USABLE FREQUENCIES AND OPTIMUM WORKING FREQUENCIES DUE TO COMBINED EFFECT OF $E$ LAYER AND $F_{1}$ LAYER AT OTHER TRANSMISSION DISTANCES. 


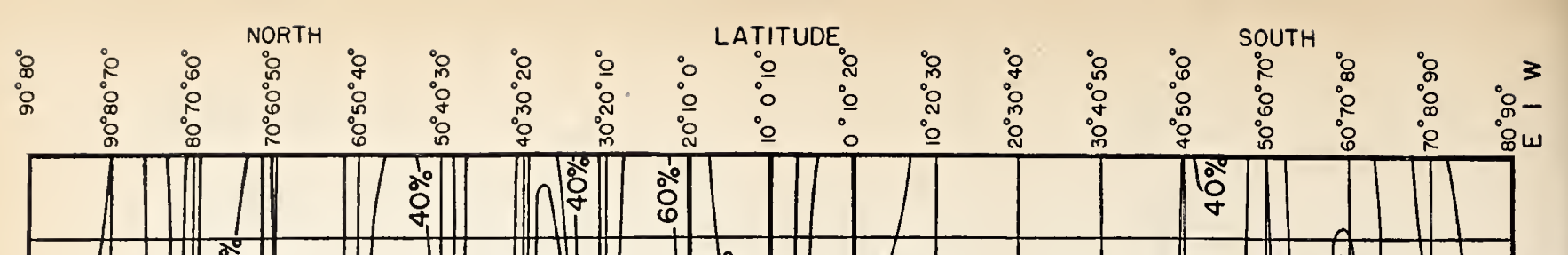

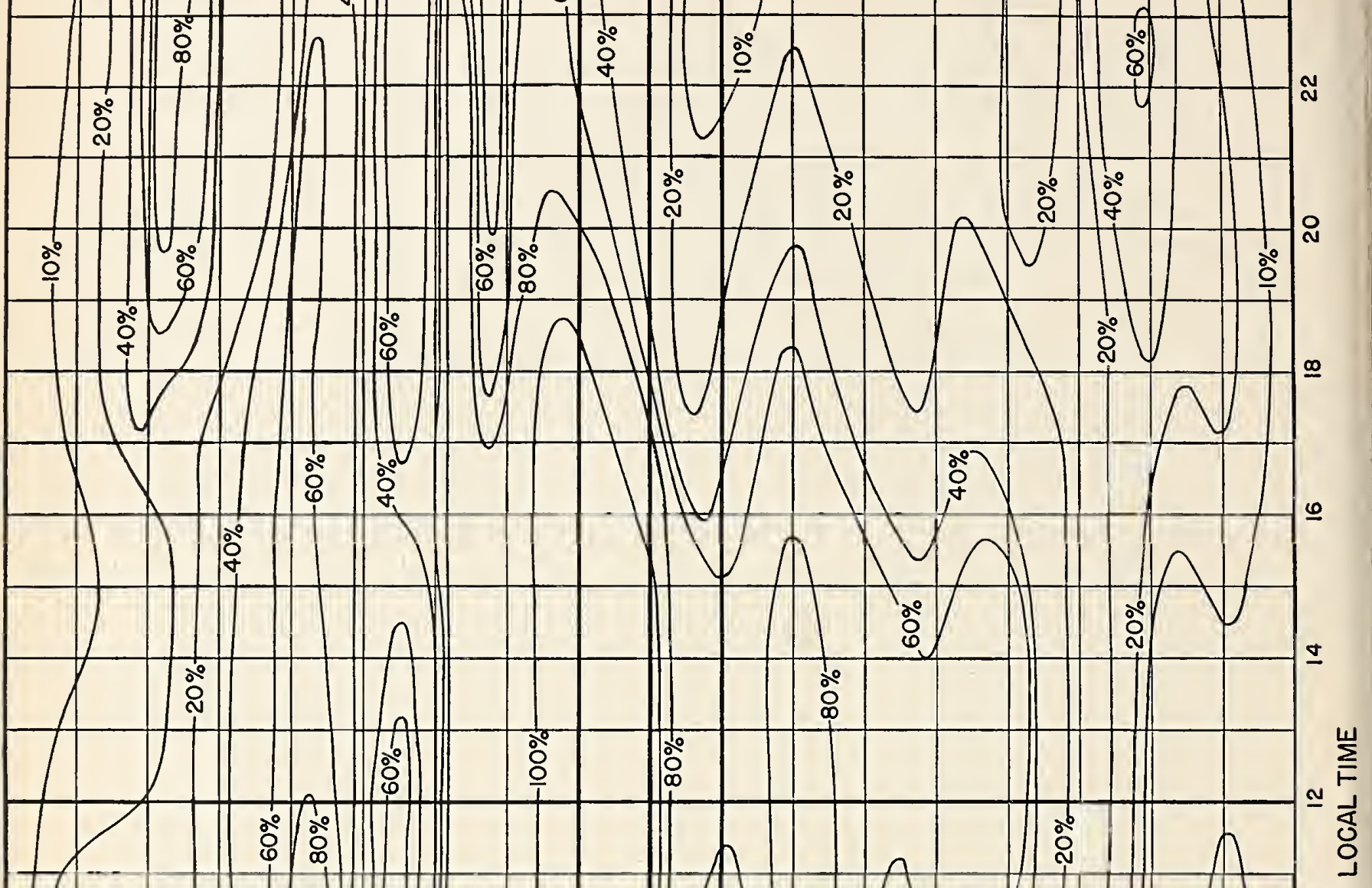

||

$\left(\frac{2}{2}\right.$

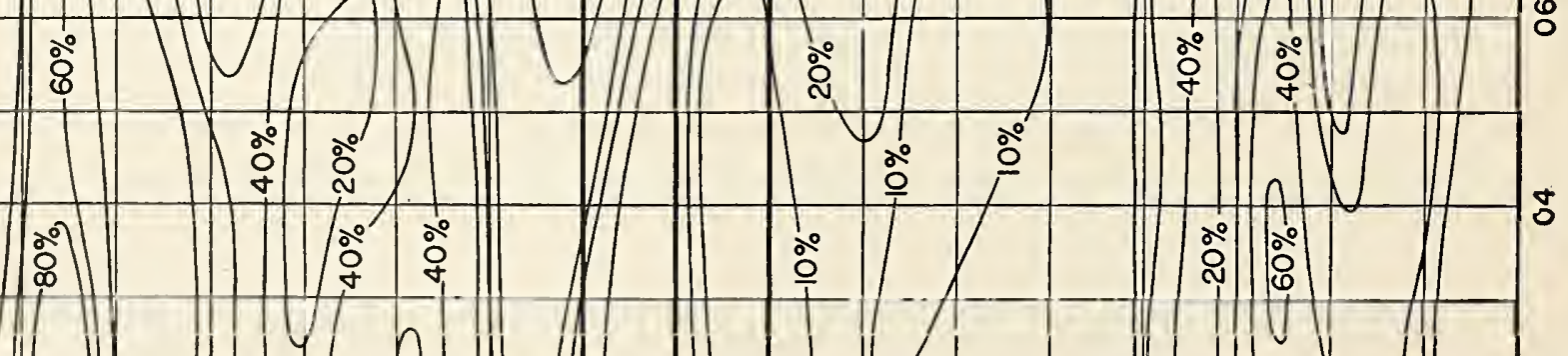

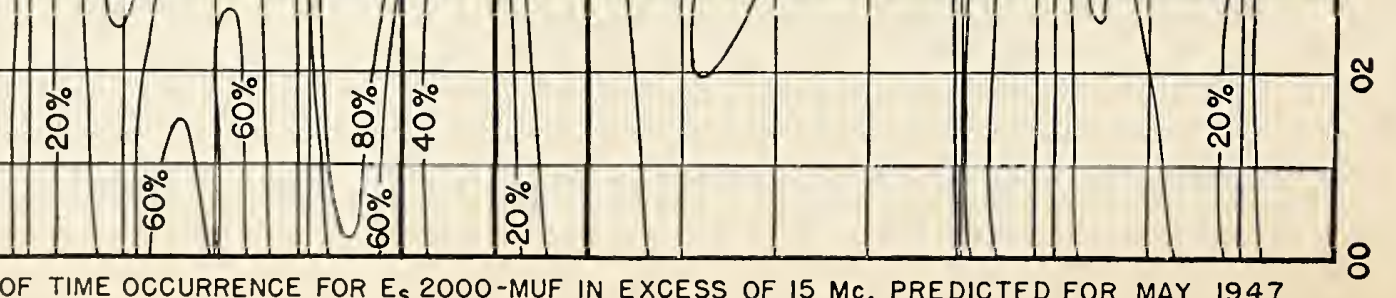

Fig. 15. PERCENTAGE OF TIME OCCURRENCE FOR $E_{s} 2000$-MUF IN EXCESS OF 15 MC, PREDICTED FOR MAY 1947. 

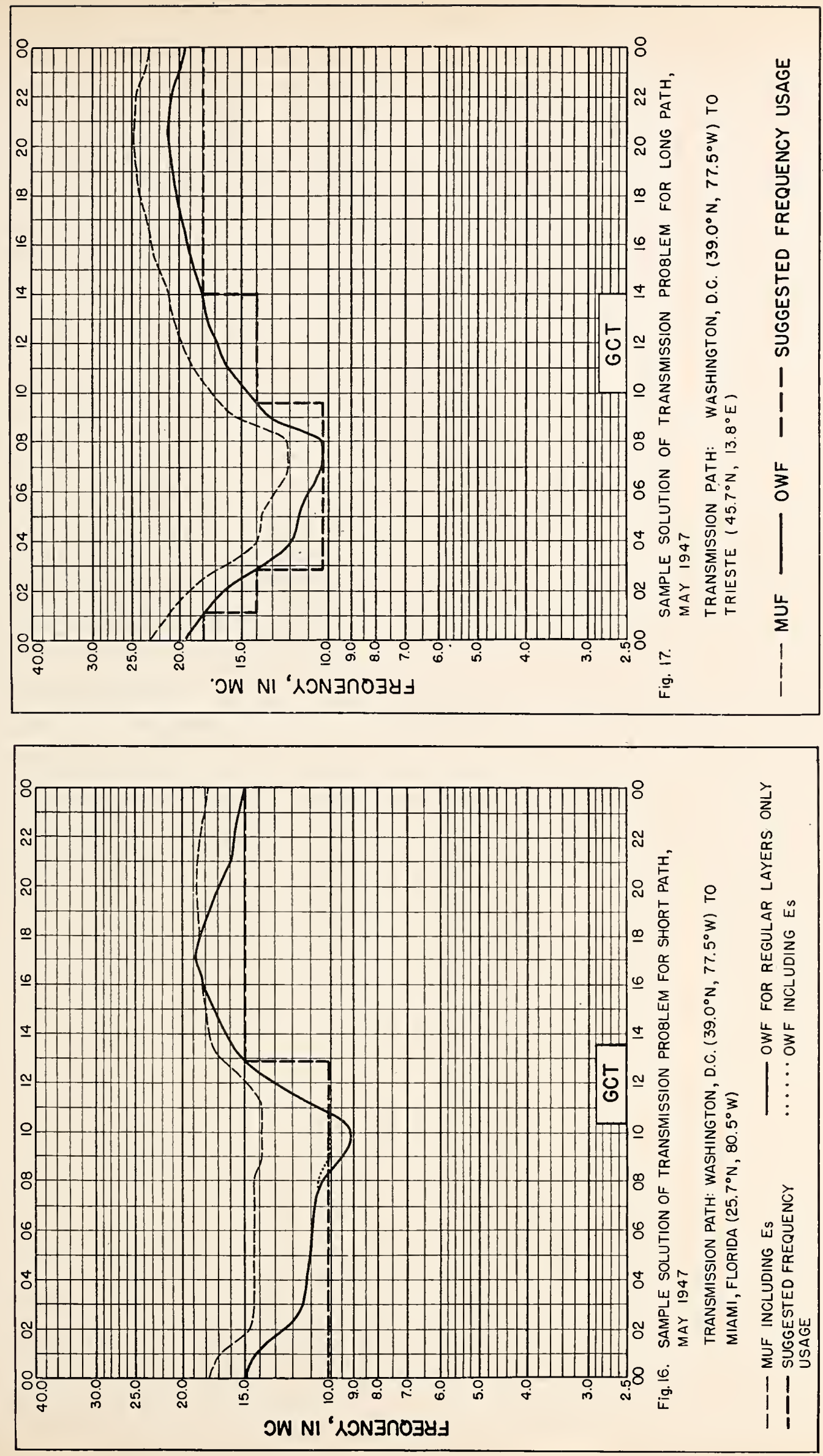

Daily:

\section{CRPL and IRPL REPORTS}

Radio disturbance warnings, every half hour from broadcast station WWV of the National Bureau of Standards.

Telephoned and telegraphed reports of ionospheric, solar, geomagnetic and radio propagation data.

Weekly:

CRPL-J. Radio Propagation Forecast (of days most likely to be disturbed, during following month).

Semimonthly:

CRPL-Ja. Semimonthly Frequency Revision Factors for CRPL Basic Radio Propagation Prediction Reports.

Monthly:

CRPL-D. Basic Radio Propagation Predictions-Three months in advance. (War Dept. TB 11-499-, monthly supplements to TM 11-499; Navy Dept. DNC-13-1 ( ), monthly supplements to DNC-13-1.)

CRPL F. Ionospheric Data.

Quarterly:

*IRPL-A. Recommended Frequency Bands for Ships and Aircraft in the Atlantic and Pacific.

*IRPI-H. Frequency Guide for Operating Personnel.

Reports on Ionospheric Measurement Standards.

Reports on Microwave Measurement Standards.

Reports Issued in Past:

IRPL Radio Propagation Handbook, Part 1. (War Dept. TM 11-499; Navy Dept. DNC-13-1.)

IRPI-C61. Report of the International Radio Propagation Conference, 17 April to 5 May 1944.

IRPL-G1 through G12. Correlation of D. F. Errors With Ionospheric Conditions.

IRPL-R. Unscheduled reports:

R4. Methods Used by IRPL for the Prediction of Ionospheric Characteristics and Maximum Usable Frequencies.

R5. Criteria for Ionospheric Storminess.

R6. Experimental Studies of Ionospheric Propagation as Applied to the Loran System.

R7. Second Report on Experimental Studies of Ionospheric Propagation as Applied to the Loran System.

R8. The Prediction of Usable Frequencies Over a Path of Short or Medium Length, Including the Effects of $E s$.

R9. An Automatic Instantaneous Indicator of Skip Distance and MUF.

R10. A Proposal for the Use of Rockets for the Study of the Ionosphere.

R11. A Nomographic Method for Both Prediction and Observation Correlation of Ionosphere Characteristics.

R12. Short Time Variations in Ionospheric Characteristics.

R13. Ionospheric and Radio Propagation Disturbances, October 1943 Through February 1945.

R14. A Graphical Method for Calculating Ground Reflection Coefficients.

R15. Predicted Limits for F2-layer Radio Transmission Throughout the Solar Cycle.

R16. Predicted F2-layer Frequencies Throughout the Solar Cycle, for Summer, Winter, and Equinox Season.

R17. Japanese Ionospheric Data-1943.

R18. Comparison of Geomagnetic Records and North Atlantic Radio Propagation Quality Figures-October 1943 Through May 1945.

R19. Nomographic Predictions of F2-laver Frequencies Throughout the Solar Cycle, for June.

R20. Nomographic Predictions of $F 2$-layer Frequencies Throughout the Solar Cycle, for September.

R21. Notes on the Preparation of Skip-Distance and MUF Charts for Use by Direction-Finder Stations. (For distances out to $4000 \mathrm{~km}$.)

R22. Nomographic Predictions of F2-layer Frequencies Throughout the Solar Cycle, for December.

R23. Solar-Cycle Data for Correlation With Radio Propagation Phenomena.

R24. Relations Between Band Width, Pulse Shape and Usefulness of Pulses in the Loran System.

R25. The Prediction of Solar Activity as a Basis for Predictions of Radio Propagation Phenomena.

R26. The Ionosphere as a Measure of Solar Activity.

R27. Relationships Between Radio Propagation Disturbance and Central Meridian Passage of Sunspots Grouped by Distance From Center of Disc.

R28. Nomographic Predictions of F2-layer Frequencies Throughout the Solar Cycle, for January.

R29 and 29-A. Revised Classification of Radio Subjects Used in National Bureau of Standards and First Supplement (N. B. S. Letter Circukar LC-814 and Supplement, superseding Circular C385).

R30. Disturbance Rating in Values of IRPL Quality-Figure Scale From A. T. \& T. Co. Transmission Disturbance Reports to Replace T. D. Figures as Reported.

R31. North Atlantic Radio Propagation Disturbances, October 1943 Through October 1945.

R32. Nomographic Predictions of F2-layer Frequencies Throughout the Solar Cycle, for February.

R33. Ionospheric Data on File at IRPL.

R34. The Interpretation of Recorded Values of $f E s$.

R35. Comparison of Percentage of Total Time of Second-Multiple Es Reflections and That of $f E s$ in Excess of 3 Mc.

IRPL-T. Reports on Tropospheric Propagation.

T1. Radar Operation and Weather. (Superseded by JANP 101.)

T2. Radar Coverage and Weather. (Superseded by JANP 102.)

CRPL-T3.' Tropospheric Propagation and Radio-Meteorology. (Reissue of Columbia Wave Propagation Group WPG-5.)

Items bearing this symbol are distributed only by U. S. Navy in NONREGISTERED PUBLICATIONS MEMORANDA (NRPM). IRPL-A and $-\mathrm{H}$ issued under one cover with NRPM identifying numbers. 
